\title{
Intrathalamic Rhythmicity Studied in vitro: Nominal T-Current Modulation Causes Robust Antioscillatory Effects
}

\author{
J. R. Huguenard and D. A. Prince \\ Department of Neurology and Neurological Sciences, Stanford University Medical Center, Stanford, California 94305
}

Thalamocortical oscillations mediate both physiological and pathophysiological behaviors including sleep and generalized absence epilepsy (GA). Reciprocal intrathalamic circuitry and robust burst firing, dependent on underlying transient Ca current $\left(I_{T}\right)$ in thalamic neurons, support generation of such rhythms. In order to study the regulation of intrathalamic rhythm generation and the effects of GA anticonvuisants previously shown to reduce $I_{T}$ in acutely isolated thalamic neurons, we developed an in vitro rat thalamic slice preparation that retains sufficient intrathalamic circuitry to support evoked oscillations (range $=2.0-4.6 \mathrm{~Hz}$, average = $2.7, n=38$ ), associated with burst firing in the thalamic reticular nucleus (nRt) and thalamic relay neurons.

Extracellular stimulation of $n R t$ evoked in relay neurons a biphasic inhibitory response with prominent $\mathrm{GABA}_{\mathrm{A}}$ and $\mathrm{GABA}_{B}$ receptor-mediated components. The GABA $\mathrm{A}_{A}$ component was picrotoxin sensitive, outwardly rectifying and $\mathbf{C l}-$ dependent, with a very negative reversal potential ( $-94 \mathrm{mV}$ ), indicating that an active extrusion mechanism exists in these cells to keep [Cl $]_{i}<5 \mathrm{~mm}$. The $\mathrm{GABA}_{\mathrm{B}}$ component had a linear conductance, a reversal potential of $-103 \mathrm{mV}$, and was quite long lasting (about $300 \mathrm{msec}$ ) so that rebound bursts often were generated on its decay phase, presumably leading to reexcitation of $\mathrm{nRt}$ through known excitatory connections. $\mathrm{GABA}_{\mathrm{B}}$-mediated responses thus provide a timing mechanism for promoting slow intrathalamic oscillations.

Reduction of $I_{T}(30-40 \%)$ by succinimides slightly increased the threshold for burst generation in relay and $\mathrm{nRt}$ cells, but there was little effect on either number of spikes/ burst or intraburst frequency, and there were no other direct effects on other measures of cellular excitability. Intrathalamic oscillations were significantly reduced by these agents through a slight decrease in burst probability of thalamic neurons. We conclude that interactions between the intrinsic properties of thalamic neurons and intrathalamic circuitry lead to generation of slow oscillations. A similar mechanism may underlie the pathophysiological $3 \mathrm{~Hz}$ spike and wave EEG activity that characterizes GA. Furthermore, anti-GA

\footnotetext{
Received Nov. 10, 1993; revised Feb. 9, 1994; accepted Mar. 15, 1994.

We thank E. Brooks, L. Bercutt, and I. Parada, who provided technical assistance, and C. L. Cox, who kindly read an earlier version of the manuscript. Special thanks to Y. De Koninck and I. Mody for helpful discussions rcgarding analysis of $\mathrm{GABA}_{\mathrm{B}}$-mediated synaptic currents. This work was supported by National Institutes of Health Grants NS06477 and NS12151 from the NINDS, and the Morris and Pimley Research Funds.

Correspondence should be addressed to J. R. Huguenard, Ph.D., Department of Neurology and Neurological Sciences, Room M016, Stanford University Medical Center, Stanford, CA 94305.

Copyright (C) 1994 Society for Neuroscience $0270-6474 / 94 / 145485-18 \$ 05.00 / 0$
}

drugs such as ethosuximide probably exert their action by reducing the burst-firing probability of neurons within populations of reciprocally interconnected relay and $n R t$ neurons, thus producing a desynchronization of the thalamic circuit that prevents spike/wave generation.

[Key words: T-current, low-threshold spike, thalamus, succinimide anticonvulsants, burst firing, oscillation, absence epilepsy]

The thalamus participates in the generation of rhythmic cortical activities such as sleep spindles (7-14 Hz in cat; Andersen et al., 1967; Steriade and Llinás, 1988) and spike-wave activity of generalized absence (GA) epilepsy (Williams, 1953; Pollen, 1964; Steriade et al., 1976; Avoli and Kostopoulos, 1982; Avoli et al., 1983; McLachlan et al., 1984b; Pellegrini et al., 1985; Vergnes et al., 1987; Avanzini et al., 1992; Inoue et al., 1993). Spindles are absent in cortex that has been disconnected from the thalamus (Burns, 1950) but are present in the thalamus of decorticate animals (Morison and Basset, 1945), showing that this structure is essential for spindle generation. In contrast to spindles, which are initiated in the thalamus, the spike-wave discharges of GA require functional connectivity between cortex and thalamus (reviewed in Gloor and Fariello, 1988). The electroencephalographic signature of human GA is a $3 \mathrm{~Hz}$ spike and wave rhythm consisting of bilaterally synchronous activity with a relatively sharp spike ( $10-40 \mathrm{msec}$ duration) followed by a slow wave. In animal models, the former is associated with neocortical and thalamic relay unit firing, while the 150-300 msec slow wave is gencrally associated with intracortical and intrathalamic inhibition and cessation of unit firing (Prince, 1972; Steriade, 1974; Steriade and Yossif, 1974; Steriade et al., 1976; Fisher and Prince 1977a,b; Avoli et al., 1983). Similar EEG activity can be elicited by low-frequency stimulation of midline thalamic structures (Jasper and Droogleever-Fortuyn, 1947).

Multiple lines of evidence indicate that common circuitry and intrinsic mechanisms underlie spindle rhythm and $3 \mathrm{~Hz}$ spike and wave of GA epilepsy. (1) The occurrence of spike waves in the human EEG is highly correlated with spindle sleep periods (Kellaway, 1985). (2) Spindle-like activity that occurs within in vitro brain slices can be transformed into slower rhythms resembling spike waves by simply decreasing $\mathrm{GABA}_{\mathrm{A}}$-mediated inhibition (von Krosigk et al., 1993). (3) A similar phenomenon occurs in the feline penicillin generalized epilepsy model produced by parenteral injection of penicillin (Prince and Farrell, 1969), where there is a gradual evolution of EEG activity from sleep spindles to spike/wave complexes (McLachlan et al., 1984a). (4) Prominent synchronized burst activity occurs in relay neu- 
rons during spindle sleep (Livingstone and Hubel, 1981; Hirsch et al., 1983) and also in animal models of GA (Inoue et al., 1993). (5) We have shown that antiepileptic drugs that are specific for the treatment of GA, but not other forms of epilepsy, block the low-threshold calcium current $\left(I_{\mathrm{T}}\right)$ responsible for burst firing in relay neurons (Coulter et al., 1989a,b, 1990a; Huguenard and Prince, 1992a), implicating the burst-firing mode as a prominent pharmacological target in GA.

The mechanisms underlying intrinsic burst firing in thalamic neurons have been described in detail. Briefly, during periods of slow-wave sleep, relay neurons hyperpolarize (Hirsch et al., 1983) and undergo a dramatic change in their firing properties (Livingstone and Hubel, 1981; Hirsch et al., 1983) such that responses involving generation of regular spikes (linear or relay firing mode) are replaced by generation of intrinsic burst discharges (nonlinear burst-firing mode). The latter patterns of activity result from $\mathrm{Ca}^{2+}$-dependent low-threshold spikes (LTSs; Deschênes et al., 1982; Llinás and Jahnsen, 1982) generated by a transient calcium current $\left(I_{\mathrm{T}}\right.$; Coulter et al., 1989c). Each LTS can trigger multiple $\mathrm{Na}^{+}$-dependent action polentials. Although there have been no published in vivo thalamic intracellular recordings during experimental or human GA, extracellular recordings indicate that thalamic neurons fire in burst mode during periods of spike-wave activity (Gloor et al., 1975; Buzsaki, 1991; Inoue et al., 1993).

Actions on Ca-dependent burst firing in relay neurons during GA are the putative basis for the pharmacological efficacy of ethosuximide and related anti-GA compounds (Coulter et al., $1989 \mathrm{a}, \mathrm{b}$ ). An additional sitc of action is in $\mathrm{nRt}$, a shell-like group of GABAergic inhibitory neurons that surrounds the anterior and lateral aspects of dorsal thalamus (Jones, 1985). The neurons within sectors of $\mathrm{nRt}$ are reciprocally connected with excitatory neurons of the corresponding sensory relay nuclei (Montero et al., 1977; Jones, 1985; Mitrofanis and Guillery, 1993). nRt cells also possess transient calcium currents that underlie their prominent $\mathrm{Ca}$-dependent burst firing. Although the T-currents in $\mathrm{nRt}$ and relay cells differ in their biophysical properties (Coulter et al., 1989c; Huguenard and Prince, 1992a), they are both sensitive to blockade by specific GA therapeutic agents (Coulter et al., 1989a,b, 1990a; Huguenard and Prince, 1992a).

On the basis of results from experiments employing acutely isolated thalamic neurons (Coulter et al., 1989a,b, 1990a; Huguenard and Prince, 1992a) we have hypothesized that ethosuximide-mediated reduction in T-current results in diminished Ca-depcndent burst firing in relay cells (Coulter et al., 1989a) and nRt neurons (Huguenard and Prince, 1992a), and that the net result is a quenched intrathalamic and thalamocortical oscillation. To test this hypothesis further, and to examine the regulatory mechanisms for thalamic synchronization, we developed an in vitro thalamic slice preparation, containing interconnected VB and nRt neurons, which is capable of sustained low-frequency $(2-4 \mathrm{~Hz})$ oscillations. Using "blind" patchclamping techniques (Blanton et al., 1989; Otis et al., 1991), we obtained current and voltage recordings from both relay neurons and $\mathrm{nRt}$ neurons and examined the effects of succinimide anticonvulsants on $\mathrm{Ca}$-dependent burst firing, and on synaptically driven, intrathalamic oscillations. We find that the reductions in T-current produced by such agents have minimal effect on individual Ca-dependent bursts in both relay and $\mathrm{nRt}$ cells. Succinimides do cause a slight reduction in the probability of triggering LTSs; however, once generated, they were practically indistinguishable from control. Nonetheless, these small reduc- tions in the burst-firing probabilities within $\mathrm{nRt}$ and relay neurons were associated with markedly dampened oscillations within the network. These effects may explain the thalamic desynchronizing effect of ethosuximide seen in vivo (Pellegrini et al., 1989), and its clinical effectiveness in GA.

\section{Materials and Methods}

In vitro tissue slice preparation. All experiments were performed in horizontal rat brain slices taken through the middle portion of $\mathrm{nRt}$ (stereotaxic levels $4.6-5.82 \mathrm{~mm}$ below bregma; Paxinos and Watson, 1986) that contained the adjacent ventral posterior lateral nucleus. Gravid Sprague-Dawley rats (Simonsen) were housed in a local animal facility in accordance with protocols approved by Stanford Institutional Animal Care and Use Committee and investigators adhered to the guidelines published in the NIH Guide for the Care and Use of Laboratory Animals. Rat pups, aged 8-26 d (p8-p26), were anesthetized $(50 \mathrm{mg} / \mathrm{kg}$ pentobarbital) and decapitated, and the brains rapidly removed and placed in chilled $\left(4^{\circ} \mathrm{C}\right.$ ) low-Ca/low-Na slicing solution consisting of (in mm) 234 sucrose, 11 glucose, $24 \mathrm{NaHCO}_{3}, 2.5 \mathrm{KCl}, 1.25 \mathrm{NaH}_{2} \mathrm{PO}_{4}, 10$ $\mathrm{MgSO}_{4}$, and $0.5 \mathrm{CaCl}_{2}$, equilibrated with a mixture of $95 \% \mathrm{O}_{2}, 5 \% \mathrm{CO}_{2}$ (Fukuda and Prince, 1992). A block of brain containing the thalamus was glued ventral surface down to the chuck of a vibratome (TPI, St. Louis, MO) and $400 \mu \mathrm{m}$ slices were obtained in a horizontal plane. The slices were incubated in $30^{\circ} \mathrm{C}$ oxygenated saline prior to being placed in an interface recording chamber that had been modified for superfusion at a rate of $2 \mathrm{ml} / \mathrm{min}$. Slices were maintained at $34 \pm 1{ }^{\circ} \mathrm{C}$ in the recording chamber and remained viable for several hours under these conditions.

Recording procedures. The standard extracellular superfusion solution consisted of (in mM) $126 \mathrm{NaCl}, 26 \mathrm{NaHCO}_{3}, 2.5 \mathrm{KCl}, 1.25 \mathrm{NaH}_{2} \mathrm{PO}_{4}$, $2 \mathrm{MgCl}_{2}, 2 \mathrm{CaCl}_{2}$, and 10 glucose; intracellular recordings were made with patch-clamp electrodes filled with the following solution: 120 $\mathrm{K}$-gluconate, $1 \mathrm{MgCl}_{2}, 1 \mathrm{CaCl}_{2}, 11 \mathrm{KCl}, 10 \mathrm{HEPES}$, and $11 \mathrm{EGTA}$. The $\mathrm{pH}$ was adjusted to 7.3 with $\mathrm{KOH}$ and osmolality to 290 with distilled $\mathrm{H}_{2} \mathrm{O}$. The low $\left[\mathrm{Cl}^{-}\right]$of the pipette solution resulted in a $10 \mathrm{mV}$ liquid junction potential and intracellular potentials were corrected by subtracting $10 \mathrm{mV}$ from the measured potentials (Hagiwara and Ohmori, 1982), except for the experiments shown in Figure 6. Electrodes were fabricated from borosilicate glass (KG-33, o.d. $1.5 \mathrm{~mm}$, i.d. $1.0 \mathrm{~mm}$, Garner Glass, Claremont, CA), and had resistances of 4-6 M $\Omega$ in the bath.

Whole cell patch-clamp recordings were obtained without the benefit of visual control (Blanton et al., 1989; Otis et al., 1991). During recordings, electrode access resistance could spontaneously increase, causing a deterioration of the quality of the recording. Results were rejected in current-clamp experiments when access resistance, measured by bridgebalance, increased to more than $70 \mathrm{M} \Omega$, or in voltage-clamp when access resistance increased beyond the point that switching frequencies greater than $3 \mathrm{kHz}$ were impossible. This corresponded to approximately 30 $\mathrm{M} \Omega$ access resistance. An Axoclamp 2A (Axon Instruments, Foster City, CA) was used for bridge mode voltage recordings as well as switched (discontinuous) single-electrode voltage-clamp recordings. The headstage monitor was continually observed to ensure essentially complete decay of the current transient prior to voltage measurement. Switching frequencies of 3-8 kHz with clamp gains of $0.3-1.5 \mathrm{nA} / \mathrm{mV}$ were used. Phase lag with a time constant of $2-20 \mathrm{msec}$ was normally used to increase the stability of the clamp at the expense of a slight reduction in frequency response. In general, patch electrode intracellular recordings in slices maintained in vitro were of high quality. Resting potentials were stable and more negative than $-55 \mathrm{mV}$ (mean $\pm \mathrm{SD}=-71.2 \pm$ $6.0 \mathrm{mV}, n=162)$ and input resistances were greater than $60 \mathrm{M} \Omega(152$ $\pm 58 \mathrm{M} \Omega, n=83$ ). The limiting factor for these recordings was increases in pipette access resistance, as above, rather than deterioration of cell properties. Population data are given as average $\pm \mathrm{SD}$, and $n=$ numbers of cells.

Extracellular stimuli were delivered through a pair of 1-10 M $\Omega$ sharpened tungsten electrodes (FHC) glued together with a separation of about $100 \mu \mathrm{m}$. Extracellular unit and multiunit recordings were obtained with $5-10 \mathrm{M} \Omega$ tungsten electrodes and normally filtered between $100 \mathrm{~Hz}$ and $3 \mathrm{kHz}$. Drugs and chemicals were applied by bath perfusion. The recording chamber volume exchange time was approximately $3 \mathrm{~min}$. Ethosuximide was a kind gift from C. Germain (Parke Davis, Ann Arbor, MI). All other compounds were obtained from Sigma Chemical (St. Louis, MO). 


\section{Results}

Effects of T-channel blockers on low-threshold $\mathrm{Ca}^{2+}$ spikes Initial experiments were designed to confirm, in intact thalamic neurons, the essential findings previously obtained in acutely isolated neurons - namely, that ethosuximide (ES) and related compounds block $I_{\mathrm{T}}$. The activation threshold for $I_{\mathrm{T}}$ is relatively negative, that is, less depolarized, compared to other currents in relay cells, especially other transient currents such as $I_{\mathrm{A}}(\mathrm{Hu}-$ guenard et al., 1991). Thus, extensive pharmacological manipulations to isolate $I_{\mathrm{T}}$ were not required, since it could be activated with small depolarizations into the range near $-60 \mathrm{mV}$ that did not activate other currents. In most neurons, however, there was obvious loss of voltage control (cf. Huguenard et al., 1988) during attempts to clamp $I_{\mathrm{T}}$. Because $I_{\mathrm{T}}$ is inward and its activation leads to a regenerative LTS, and especially because these experiments were carried out at a warm temperature $\left(34^{\circ} \mathrm{C}\right)$, which increases both the size and activation rate of $I_{\mathrm{T}}$ (Coulter et al., 1989c), very large and notched inward currents were often obtained. Smoothly activating and inactivating currents (i.e., without notches) were obtained in some cells when access resistance was low $(<15 \mathrm{M} \Omega)$, the voltage clamp gain was maximized $(0.3-1.0 \mathrm{nA} / \mathrm{mV})$, and the size of the evoked current was reduced by depolarization of the holding potential (to steady state inactivated most of the current; cf. Coulter et al., 1989c). Examples of well-clamped $\mathrm{T}$-currents in a ventrobasal relay neuron and an nRt cell are shown in Figure 1. The progressive reduction in $I_{\mathrm{T}}$ amplitude, with little change in the time course of the current, that occurs in the relay neuron (Fig. 1 $\mathrm{A}$ ) with the steady-state inactivation protocol is evidence of reasonable voltage control (Coulter et al., 1989c; Huguenard and Prince, 1992a). ES, at a concentration of $700 \mu \mathrm{M}$, reversibly reduced the amplitude of the maximal $I_{\mathrm{T}}$ (arrows) obtained at the most negative holding potential, but also reduced the amplitude at all prepotentials, thus confirming that this drug reduces $I_{\mathrm{T}}$. The maximum reduction seen under these conditions was about $33 \%$. Furthermore, as in isolated neurons (Coulter et al., 1989a,b), the effect of ES was not accompanied by any change in the kinetics or steady-state inactivation. Similar effects were seen with another GA drug, methyl-phenyl succinimide, the active metabolite of methsuximide (Coulter et al., 1990a; Huguenard and Prince, 1992a), at concentrations of 200-800 $\mu \mathrm{M}(n=4$, not shown).

A slowly inactivating form of transient $\mathrm{Ca}^{2+}$ current, $I_{\mathrm{Ts}}(\mathrm{Hu}-$ guenard and Prince, 1992a), occurs in $n R t$ neurons, where it promotes relatively prolonged $\mathrm{Ca}^{2+}$-dependent bursts, and it was also blocked by ES (Fig. $1 C$ ). In the example shown, clamp control was improved by depolarizing the holding potential so that $I_{\mathrm{Ts}}$ was $>90 \%$ inactivated (Huguenard and Prince, 1992a), and applying only a small command step. ES reversibly (see wash in Fig. $1 C 3$ ) reduced $I_{\mathrm{T} s}$ to $41 \%$ of control, about the same extent as it decreased $I_{\mathrm{T}}$ in relay neurons. The reduction in current was not caused by an alteration in kinetics of activation or inactivation, since the normalized traces were essentially overlapping (Fig. 1C3). The time course and reversibility of the ES effect are clearly seen with the time series in Figure $1 C 2$. Thus, we confirm that ES reduces T-current in "intact" relay and $\mathrm{nRt}$ cells in slices maintained in vitro, and conclude that the reduction is not an artifact of the methods for preparing isolated thalamic neurons or recording from them in previous experiments.

The difficulty in obtaining adequate voltage-clamp control during T-current activation led us to an alternative approach to assessing $T$-current availability, that of measuring the rate of rise of single LTSs (Jahnsen and Llinás, 1984). Since the rate of rise is dependent on the current flow and membrane capacitance $\left(d V / d t=I_{m} / C_{m}\right)$, and capacitance is presumably constant, the differentiated voltage is dircetly proportional to current. If we assume that $I_{\mathrm{T}}$ is the predominant current activated during the rising phase of the LTS, then relative changes in $I_{\mathrm{T}}$ amplitude can be readily measured as the maximal rate of rise. While using this approach, current pulses were adjusted to activate a small LTS that was subthreshold for $\mathrm{Na}^{+}$spikes, and resting membrane potential was continuously monitored and adjusted to the control level to ensure that the fraction of steady-state available channels was constant. ES only slightly reduced LTS amplitude (Fig. $1 B 1 a$ ), but the rate of rise of single LTSs was reduced by ES (Fig. $1 B 1 b, B 2$ ) to essentially the same extent as $I_{\mathrm{T}}, 32 \pm$ $13 \%(n=13)$. The effect on LTSs was rapid, occurring within 2-4 min after a change in superfusion solution, essentially the same time as the bath turnover time.

Recently, a slowly activating inward current $\left(I_{\mathrm{H}}\right)$ has been described in guinea pig and cat thalamic relay neurons (Pape and McCormick, 1989; McCormick and Pape, 1990). It is turned on by hyperpolarization, and is important in regulating burst firing in these cells. We found that $I_{\mathrm{H}}$ was also present in rat relay neurons (Fig. 2) but was absent in nRt cells (not shown). The extent and rate of activation of $I_{\mathrm{H}}$ are voltage dependent, so it activates more rapidly with stronger depolarizations (Pape and McCormick, 1989; McCormick and Pape, 1990). For example, compare the large inward relaxation obtained by hyperpolarizing a VB neuron from -40 to $-110 \mathrm{mV}$ (Fig. $2 A 1$ ) to the smaller and slower relaxation obtained upon hyperpolarization to $-74 \mathrm{mV}$ (Fig. 2A3). Theoretical considerations (McCormick and Huguenard, 1992) indicate that intrinsic oscillations can occur in relay neurons largely as a result of the interaction between $I_{\mathrm{T}}$ and $I_{\mathrm{H}}$. Activation of $I_{\mathrm{T}}$ results in LTS generation and concurrent deactivation of $I_{\mathrm{H}}$. Then, following each LTS, $I_{\mathrm{H}}$ gradually reactivates, the resultant depolarization brings the membrane potential to threshold for activation of another LTS, and the cycle repeats. We hypothesized that, in addition to their effect on $I_{\mathrm{T}}$, the antioscillatory effects of succinimides might be due, in part, to interactions with $I_{\mathrm{H}}$. For example, by partially blocking $I_{\mathrm{H}}$, succinimides might affect either single LTS generation (and contribute to the effect shown in Fig. $1 B$ ) or interfere with intrinsic oscillations. Using a modeling approach (McCormick and Huguenard, 1992), we simulated alterations in both $I_{\mathrm{T}}$ and $I_{\mathrm{H}}$ (not shown) and found that while reductions in $I_{\mathrm{H}}$ amplitude or shifts in its voltage dependence of activation slightly altered the shape of a simulated LTS, only reductions in $I_{\mathrm{T}}$ reproduced the ES-induced reduction in LTS $d V / d t$. Thus modulation of $I_{\mathrm{H}}$ is unlikely to contribute to the effect of ES on burst responses. Direct evidence supported this conclusion. We found that ES (at concentrations that block $I_{\mathrm{T}}$ ) had no measurable effect on either the amplitude or time course of $I_{\mathrm{H}}$ (Fig. $2 A, B$ ).

The obvious prediction from the above experimental results is that $\mathrm{Ca}$-dependent burst firing would be markedly inhibited by concentrations of ES that reduce the T-current. The effects of ES on burst-firing capabilities in relay cells were assessed by constructing input-output $(\mathrm{i} / \mathrm{o})$ curves at a resting membrane potential of $-80 \mathrm{mV}$ (Fig. $3 A$ ) where burst firing is prominent due to strong deinactivation of thc T-current (Deschênes ct al., 1982; Llinás and Jahnsen, 1982). We used number of spikes 
A

1.

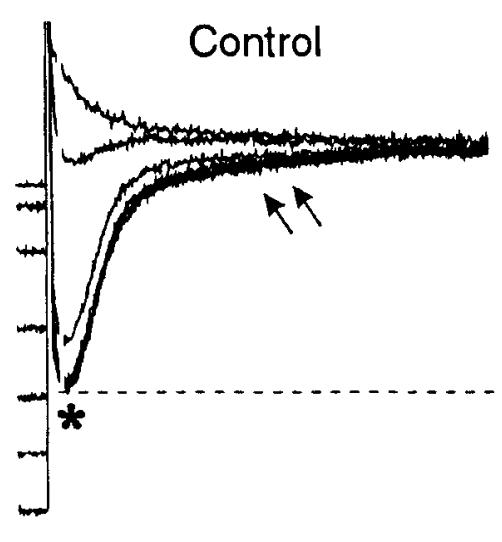

2.

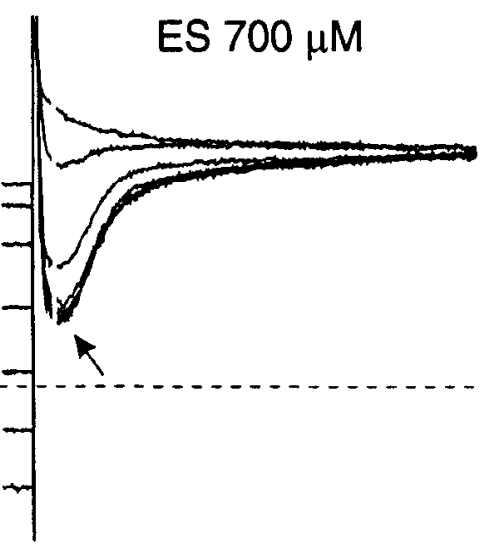

3.

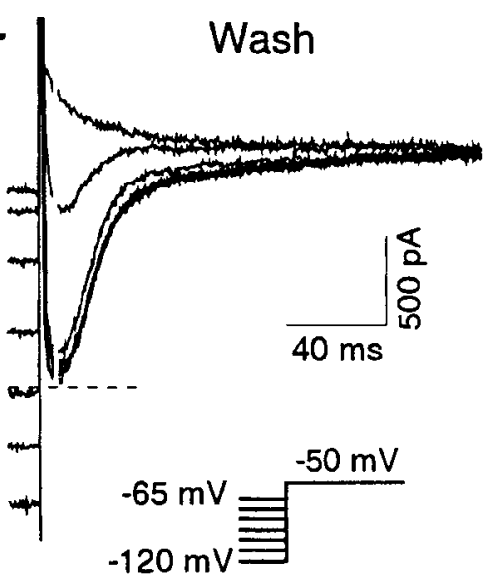

B

1. a. Control ES Wash

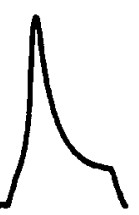

b.

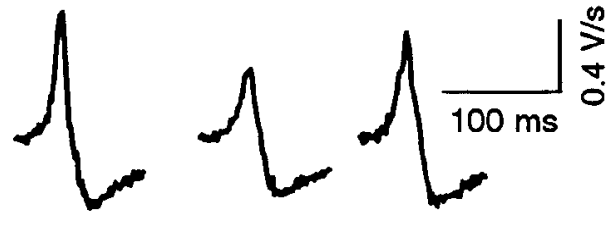

2.

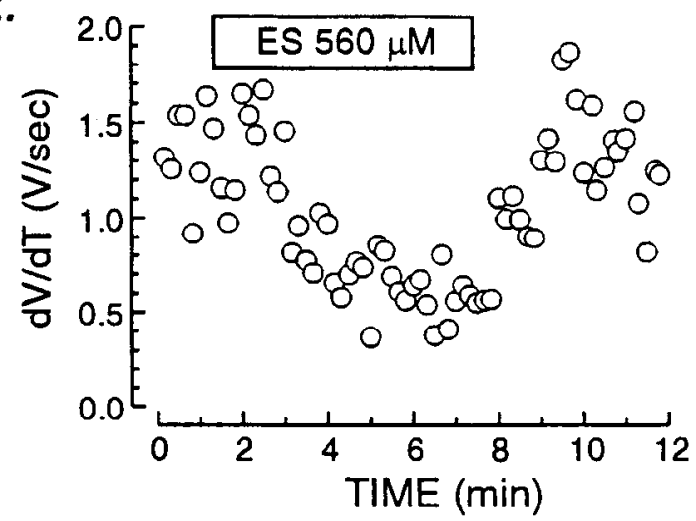

C $n R t$

1.

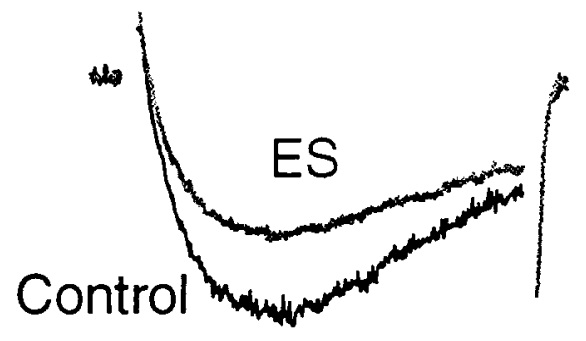

3.

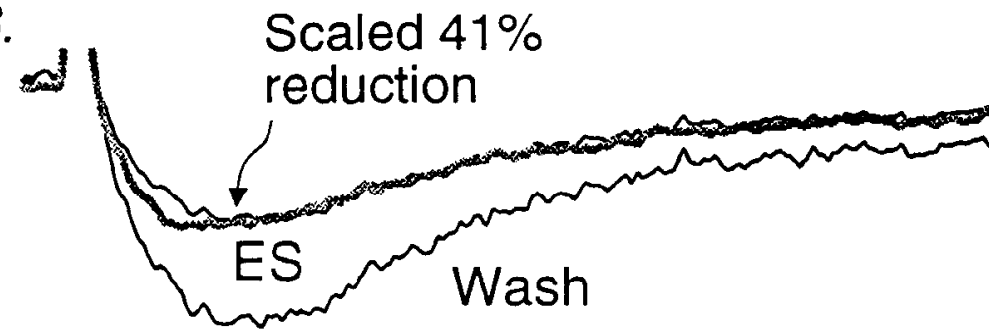

2.

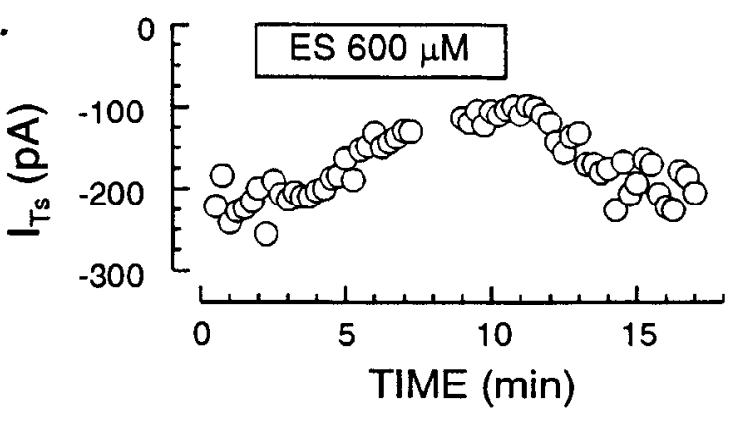

Figure 1. Ethosuximide reversibly reduces $I_{\mathrm{T}}, I_{\mathrm{Ts}}$, and low-threshold spikes in thalamic neurons within in vitro slices. $A$, T-currents evoked with a steady-state inactivation protocol (see inset at lower right) in a voltage-clamped relay neuron. A1, Control: as the holding potential was made less negative, the size of the T-current $\left(^{*}\right)$ was progressively reduced, as was the relaxation of the $\mathrm{H}$-current (arrows), which had been activated by the preceding hyperpolarization. $A 2$, ES $700 \mu \mathrm{M}$ : ES reduced the peak amplitude of the T-current (arrow), but did not affect the $\mathrm{H}$-current. $A 3$, Wash: T-currents were restored to control levels in the wash. $B$, Ethosuximide reduces low-threshold spikes. BIa, Relay neuron held at $-80 \mathrm{mV}$ in current clamp. Small LTSs were evoked by 40 pA depolarizing current pulses. Ethosuximide $(E S)$ reversibly reduced the size of LTS by $11 \%$. BIb, Electrically 


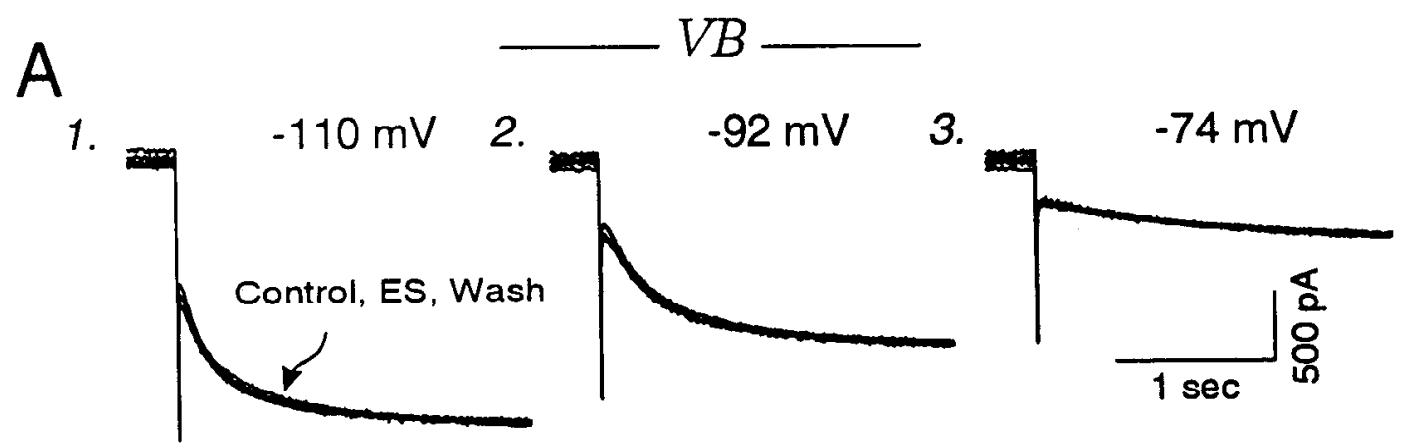

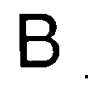

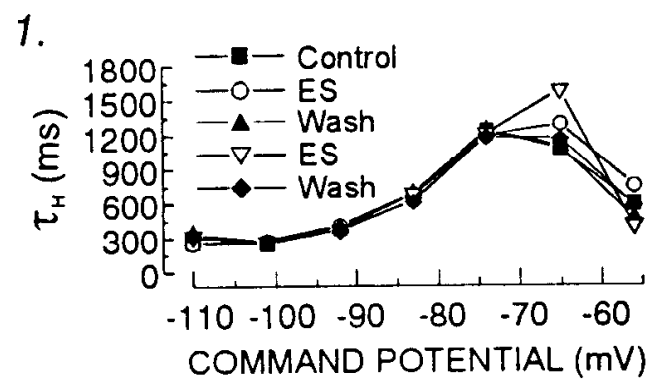

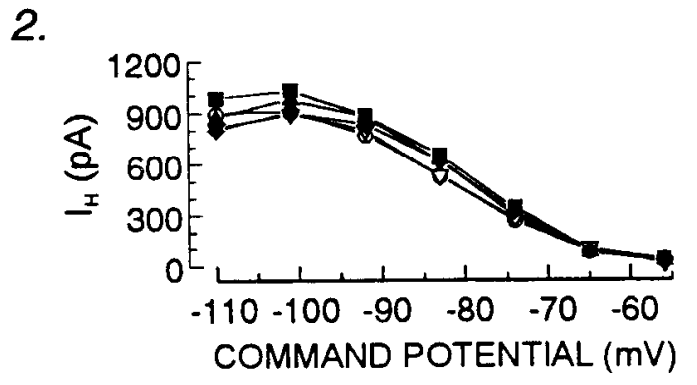

Figure 2. $I_{\mathrm{H}}$ is not affected by ES. $A$, Voltage-clamp currents evoked in a relay neuron by hyperpolarizations to the indicated potentials from a holding potential of $-40 \mathrm{mV}$. The slow inward relaxations are due to activation of $I_{\mathrm{H}}$. Five overlaid traces are shown at each potential: control, two applications of ES, and the associated washes. B1, Activation time constants for $I_{\mathrm{H}}\left(\tau_{\mathrm{H}}\right)$, measured from single exponential fits of the slowly activating current, were not affected by ES. B2, Amplitude of $I_{\mathrm{H}}$ as a function of membrane potential. ES (700 $\left.\mu \mathrm{M}\right)$ in two separate bath applications had no major effect on the amplitude or voltage dependence of $I_{\mathrm{H}}$. Same cell as in Figure $1 \mathrm{~A}$, in which there was a clear reduction in $I_{\mathrm{T}}$.

and intraburst frequency as indices of burst output mode. The $f-I$ curve (frequency vs current, Fig. $3 A 2, \square$ ) illustrates the wellknown nonlinear transfer function of relay neurons in burst mode. The threshold stimulation ( $160 \mathrm{pA})$ leads to a burst with four Na-dependent spikes (Fig. $3 A 3, \square$ ) and an intraburst frequency of $450 \mathrm{~Hz}$ (Fig. $3 A 2, \square$ ). Increasing the stimulus results in slightly higher intraburst frequencies and increases the number of spikes per burst in a stepwise fashion. For example, both 240 and 320 pA evoked five spikes (Fig. 3A3, $\square$ ), while 400, 480 , and $560 \mathrm{pA}$ each evoked six spikes. ES $(700 \mu \mathrm{M})$ results in a modest suppression of $\mathrm{Na}$ spike output in burst mode. For example, with a 480 pA stimulation, the number of spikes was reduced from six to four $(\square)$, while at $640 \mathrm{pA}$ the reduction was from seven to six spikes. The experiment illustrated in Figure $3 A$ was one of the most striking effects of ES in VB that we have seen. In this neuron, ES increased the $f / I$ slope from $110 \mathrm{~Hz} /$ $\mathrm{nA}$ to $130 \mathrm{~Hz} / \mathrm{nA}$ (Fig. $3 A 2, \square \mathrm{vs} \square$ ), and decreased the spikes/ current (sp/I) slope from 6.3 to 5.2 spikes/nA (Fig. $3 A 3$, $\square$ vs D. However, on average, there was no effect on $f / I$ slope (109 $\pm 133 \%$ of control, $n=5)$, or on $\mathrm{sp} / I$ slope $(109 \pm 69 \%$ of control). The only consistent effect of ES was a shift in the position of both $i / O$ functions similar to that shown in Figure $3, A 2$ and $A 3$. In every case, ES caused a rightward shift in the $f / I$ curve (range $=450-7900 \mathrm{pA}$ ) and the $\mathrm{sp} / I$ curve (range $=$ 10-740 pA). This is consistent with an increased threshold for
LTS activation, although the effect was indeed subtle. In no case did ES actually alter the threshold for LTS generation with these $180 \mathrm{msec}$ current injections, as is shown in Figure $3 A 1$, where the threshold stimulus was $160 \mathrm{pA}$ in control, ES, and wash.

We also examined the effect of ES on relay mode firing. When the resting membrane potential of rat VB neurons was depolarized to $-60 \mathrm{mV}$, regular repetitive spikes occurred throughout the duration of the stimulus (Fig. $3 B$ ). ES had no consistent effect on relay mode firing (Fig. $3 B$ ), either on spike threshold, adaptation (not shown), or on $f / I$ slope ( $93 \pm 12 \%$ of control, $n=5$ ).

Bursts in nRt neurons are different from those in relay cells in several ways. The former are characterized by a long-duration (50-100 msec), high-frequency $(500 \mathrm{~Hz}$ and higher) burst of $\mathrm{Na}-$ dependent spikes (Fig. $3 C$ ), with an initial acceleration of spike frequency followed by a later deceleration (Domich et al., 1986). As in relay neurons, reduction of T-currents by ES produced minimal effects on $i / o$ curves in $\mathrm{nRt}$ neurons. That is, neither the threshold nor the waveform [compare intraburst frequencies, control $(\square)$ versus ES ( $\square$ ), in Fig. 3C2] of $\mathrm{Ca}^{2+}$-dependent bursts in $\mathrm{nRt}$ were altered by concentrations of $\mathrm{ES}(700 \mu \mathrm{M})$ that blocked $30-40 \%$ of $I_{\mathrm{T} s}$. The main effect was an alteration in the latency to LTS from the onset of the intracellular current stimulus (Fig. 3C1, ES). The most prominent effects of ES are shown in Figure 3, $C 1$ and $C 2$, where the burst latency was increased

differentiated spikes. ES reduced maximum rate of rise by $40 \%$. Each trace is the average of 10 individual trials in control, ES, and wash conditions. $B 2$, Time course of ES effect for the neuron of $B 1$. C, ES blocks $I_{\mathrm{Ts}}$ in a voltage-clamped nRt neuron. $C 1$, A small $I_{\mathrm{T} s}$ was evoked with $15 \mathrm{mV}$ depolarizations from a holding potential of $-71 \mathrm{mV}$. The control current was reduced by $600 \mu \mathrm{M}$ ES, while the rate of activation and inactivation were unaffected. $C 2$, Time series depicting the onset and reversibility of the reduction in $I_{\mathrm{Ts}}$ by $600 \mu \mathrm{M}$ ES. Bar, bath perfusion of $600 \mu \mathrm{M}$ ES. $C 3$, Upon washout of the ES, $I_{\mathrm{T} s}$ returned to control levels. The wash trace (bottom), vertically scaled down by $41 \%$ (arrow) essentially overlaps the ES trace (thick line). 


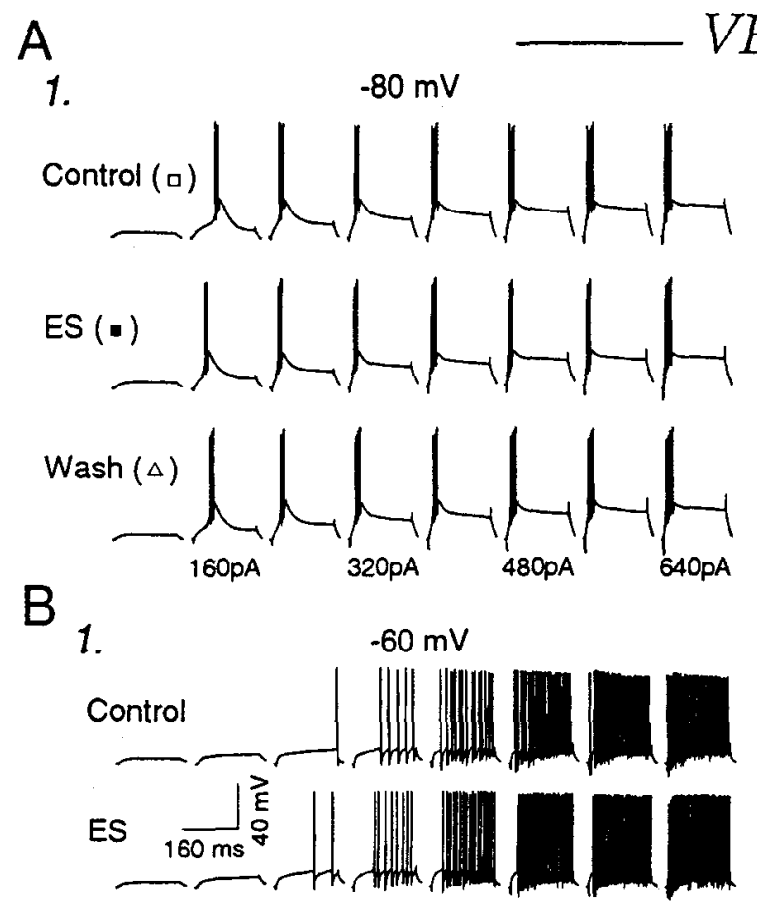

2.

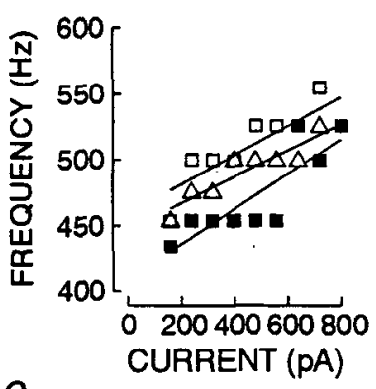

2.

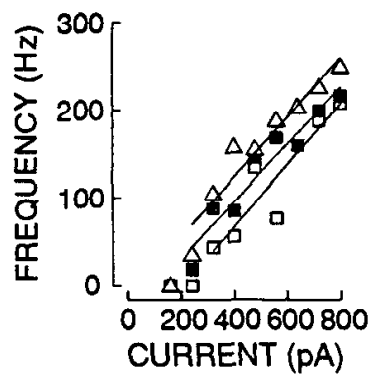

3.

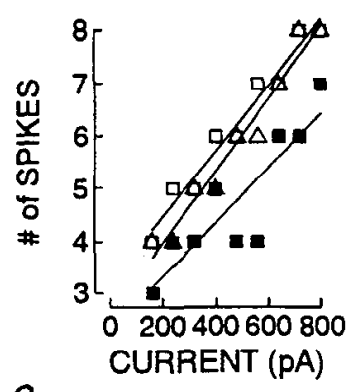

3.

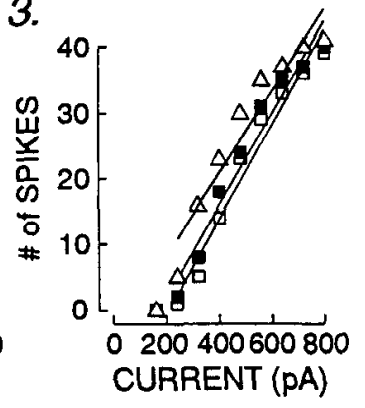

C

1.

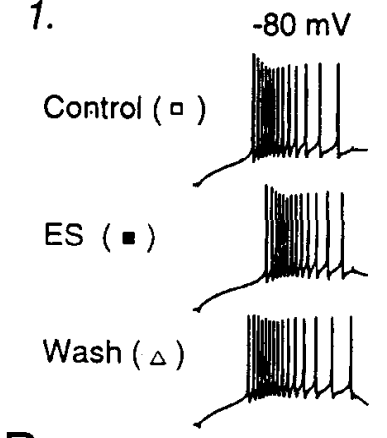

$n R t$

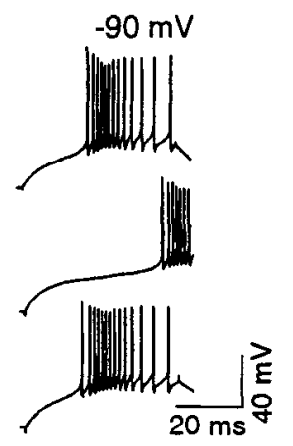

2.
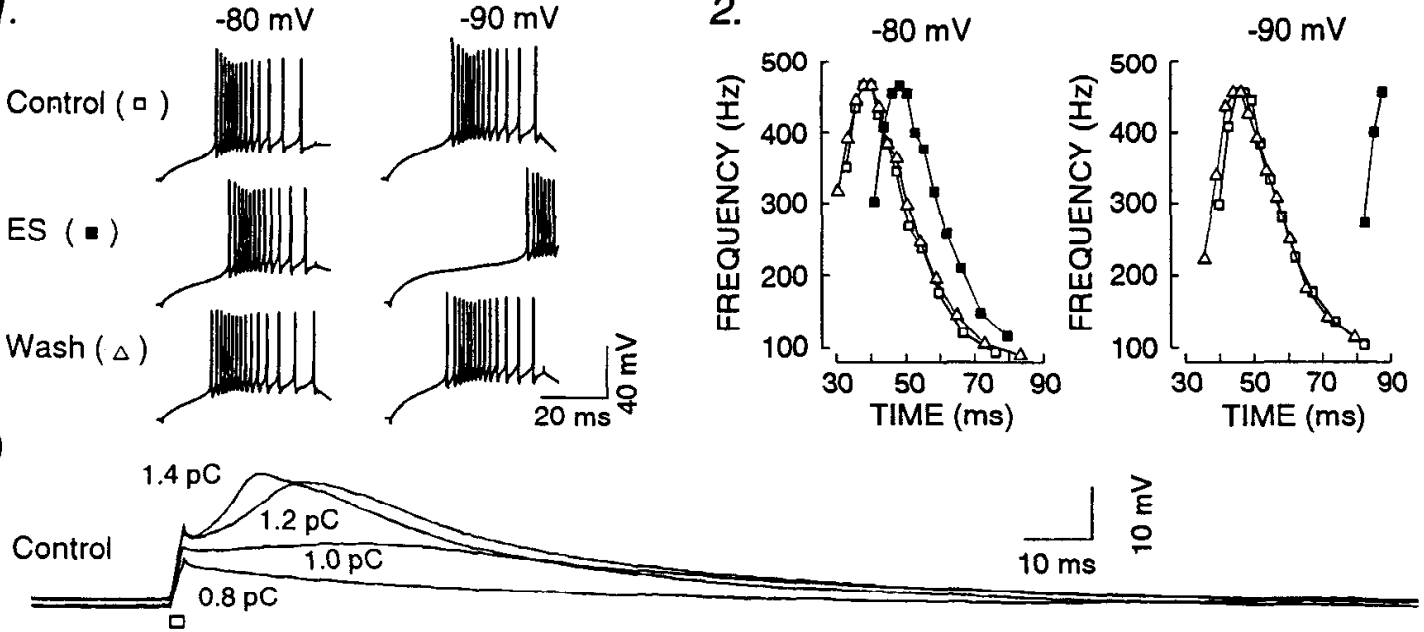

ES

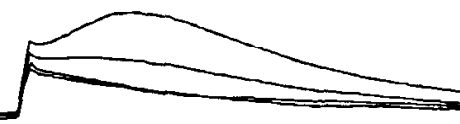

Wash

Figure 3. Current clamp recordings of effects of ES on burst- and relay-mode firing in relay $(A$ and $B)$ and nRt $(C$ and $D)$ neurons. $A 1: C o n t r o l$, A VB neuron from a P24 rat was held at a resting potential of $-80 \mathrm{mV}$, and incremental depolarizing current pulses were applied. At a threshold of $160 \mathrm{pA}$, a high-frequency $(450 \mathrm{~Hz}$ ) burst with four spikes was triggered. Larger depolarizing pulses evoked similar bursts, but with slightly higher frequencies (up to $550 \mathrm{~Hz}$ ) and numbers of spikes (up to eight). $E S$, ES $(700 \mu \mathrm{M}$ ) was added to the superfusate, and the stimulus sequence repeated. The threshold remained at $160 \mathrm{pA}$, but the initial spike frequency was slightly lower, around $430 \mathrm{~Hz}$, and the number of spikes/burst was three. Similar decreases in spikes/burst and spike frequencies versus control and wash conditions were present at nearly every stimulus intensity. $A 2$, Frequency-current $(f / I)$ curves for the experiment in $A 1$. Frequency was derived from the first interspike interval. The slopes were, for control ( $\square$ ), $110 \mathrm{~Hz} / \mathrm{nA} ; \mathrm{ES}(\square), 130 \mathrm{~Hz} / \mathrm{nA}$; and wash $(\triangle), 100 \mathrm{~Hz} / \mathrm{nA}$. In ES, the curve was shifted to the right compared to control and wash. $A 3$, Number of spikes/burst versus current intensity. At almost every intensity the number of spikes was lower in ES than in control or wash. The slopes were, for control, $6.3 \mathrm{sp} / \mathrm{nA} ; \mathrm{ES}, 5.2 \mathrm{sp} / \mathrm{nA}$; and wash, $6.9 \mathrm{sp} / \mathrm{nA}$. B1, Regular firing was not affected by ES. Same stimuli and neuron as in $A$, but the holding potential was $-60 \mathrm{mV}$. First row (control) shows a linear increase in spike numbers and frequency with increasing current injections. Traces in second row were obtained in ES, which had no consistent effect on threshold or frequency compared to control and wash (see graph of $B 2$ ). Wash traces were similar to control (not shown, but see $B 2$ and $B 3$ ). B2, ES had no effect on $f / I$ curves. The slopes were, for control, $350 \mathrm{~Hz} / \mathrm{nA}$; ES, 
with threshold stimuli at resting potentials of $-80 \mathrm{mV}$ and -90 $\mathrm{mV}$. There were no effects at higher stimulus intensities (300$500 \mathrm{pA}$ ) or at resting potentials of -70 or $-60 \mathrm{mV}$ (not shown).

The rightward shift in the $f / I$ plots (e.g., Fig. $3 A 2$ ), and the increased latency to the onset of the burst (e.g., Fig. $3 C 1$, ES at $-90 \mathrm{mV}$ ) are consistent with a slight increase in the current threshold for activation of $\mathrm{Ca}^{2+}$ bursts in thalamic neurons. For example, if there is an increased latency to burst onset (Fig. 3C), then a shorter-duration threshold current stimulus or EPSP may become subthreshold in the presence of the drug. Experiments with brief intracellular current injections $(n=4)$ confirmed this suggestion. The traces in Figure $3 D$ are examples from such an experiment. In this $\mathrm{nRt}$ neuron, $2 \mathrm{msec}$ depolarizing current pulses were incremented in amplitude until threshold for an active response was obtained. In control, the injection of 0.8 $\mathrm{pC}$ of charge produced a subthreshold response consisting of only a passive membrane response (lowest trace). Threshold was reached with $1.0 \mathrm{pC}$, and a small active response was obtained. Increasing the injected charge to $1.2 \mathrm{pC}$ resulted in near maximal activation of the $\mathrm{Ca}^{2+}$-dependent response. In the presence of ES, the threshold was increased so that 0.8 and $1.0 \mathrm{pC}$ injections both resulted in subthrcshold, passive responses while $1.2 \mathrm{pC}$ produced a small submaximal response. These threshold effects were reversible (e.g., Fig. $3 D$, wash) in all cells tested.

Surprisingly, therefore, the net effect of T-current reduction is not a major alteration in burst-mode output of relay cells or nRt neurons. Rather, there is only a slight shift in threshold current necessary to evoke an LTS; once the LTS is evoked, the burst morphology is largely unchanged. From this we conclude that there is a surplus of $I_{\mathrm{T}}$ channels in both cell types that ensures robust generation of LTSs, even in the face of moderate reduction in number of operational channels (Coulter et al., 1991). Only under conditions where LTS generation is already compromised might the $30-40 \%$ reduction in T-current be expected to inhibit burst firing (see Discussion).

\section{Inhibitory responses in relay neurons arising from activities in $n R t$}

The relatively long-duration burst response in $\mathrm{nRt}$ neurons (Fig. 3C; Avanzini et al., 1989; Shosaku et al., 1989; McCormick and Wang, 1991; Huguenard and Prince, 1992a) should evoke potent inhibitory effects in relay cells that may lead to rebound LTS generation. To test this, we developed a slice preparation with intact nRt-relay neuron connectivity. Previous results indicated that IPSPs could be elicited in coronal slices containing the anteriormost thalamus by extracellular $\mathrm{nRt}$ stimulation (Thomson, 1988). In somatosensory thalamus we found no functional connection within coronal slices. However, with horizontal slices, robust IPSPs could be readily evoked in VB by stimulation in adjacent nRt (see schematic in Fig. 8A). A small, short-latency EPSP was also occasionally seen (e.g., Fig. 8A), that presumably resulted from activation of capsular corticothalamic fibers. The IPSPs were relatively long lasting, with durations up to several hundred milliseconds. In most cases (40 of 46) the IPSPs displayed prominent early and late components with different reversal potentials. These were mediated by $\mathrm{Cl}^{-}$dependent $\mathrm{GABA}_{\mathrm{A}}$ and $\mathrm{K}^{+}$-dependent $\mathrm{GABA}_{\mathrm{B}}$ components and were similar to those seen in lateral geniculate of the cat (Crunelli et al., 1988) and rat (Hirsch and Burnod, 1987). The main difference is that in rat somatosensory thalamus they must be evoked by discharge of $\mathrm{nRt}$ neurons because there very few interneurons in VB (Jones, 1985), while in geniculate they apparently arise following activation of local circuit inhibitory interneurons because they persist in slices that are devoid of functional nRt (or perigeniculate, Crunelli et al., 1988) connections.

In voltage clamp, the early IPSC component demonstrated an outwardly rectifying $I-V$ curve (Fig. $4 A$, o) similar to that observed for $\mathrm{GABA}_{\mathrm{A}}$ responses in cultured hippocampal neurons recorded under similar conditions (Barker and Harrison, 1988 ), and was blocked by $10 \mu \mathrm{M}$ bicuculline methiodide ( $n=$ 6) and $70 \mu \mathrm{M}$ picrotoxin (Fig. $4 B, C ; n=3$ ). Reversal potential for this $\mathrm{GABA}_{\mathrm{A}}$-mediated response was very negative in these cells ( $-94 \pm 8.1, n=47$; Fig. $4 A$ ), and was dependent on the pipette $\left[\mathrm{Cl}^{-}\right]$(see Fig. 5). The late IPSC component displayed a longer latency to peak $(\sim 100 \mathrm{msec}$; Fig. $4 B)$, a more negative reversal potential $(-103 \pm 8.0 \mathrm{mV}, n=40$; Fig. $4 A)$, and a linear $I-V$ curve (Fig. $4 A$ ), and was blocked by the specific $\mathrm{GABA}_{\mathrm{B}}$ antagonist CGP 35348 (Fig. $4 B, C$ ). This $\mathrm{GABA}_{\mathrm{B}}$-mediated component had a biphasic slow decay (time constants of decay were 77 and 314 msec for the CGP35348-sensitive current in Fig. $4 D$ ) similar to that described in dentate granule cells (Otis et al., 1993). Although the $\mathrm{GABA}_{\mathrm{B}}$-mediated late synaptic response was quite large under these conditions, its conductance was only a small fraction of the earlier $\mathrm{GABA}_{\mathrm{A}}$ response. Conductance measures obtained from the slope of the $I-V$ curve at the reversal potential were $9.7 \pm 6.1 \mathrm{nS}$ (range $=0.5-30, n=$

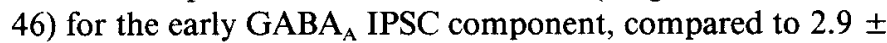
$1.8 \mathrm{nS}$ (range $=0.4-7.4, n=35$ ) for the $\mathrm{GABA}_{\mathrm{B}}$ component.

The reversal potential for the $\mathrm{GABA}_{\mathrm{A}}$ component tended to be much more negative than expected for the $15 \mathrm{~mm}$ intracellular $\left[\mathrm{Cl}^{-}\right]$and $136.5 \mathrm{~mm}$ extracellular $\left[\mathrm{Cl}^{-}\right]$solutions employed. The calculated Nernst potential is $-51 \mathrm{mV}$ when a correction factor for $\mathrm{Cl}^{-}$activity in $\mathrm{NaCl}$ solution is used. Thus, there must be mechanisms in relay cells to extrude $\mathrm{Cl}^{-}$across the membrane to the extracellular space (Thompson et al., 1988) and bring intracellular levels to down near $3 \mathrm{~mm}$. Furthermore, it appears that recording from these cells with whole-cell techniques does not guarantee that $\left[\mathrm{Cl}^{-}\right]_{i}$ will become equal to that of the patch pipette. Pipette access resistance was normally in the range of $10-20 \mathrm{M} \Omega$, and it appears that the rate of $\mathrm{Cl}^{-}$ diffusion through this pipette resistance must be too slow to

\footnotetext{
$330 \mathrm{~Hz} / \mathrm{nA}$; and wash, $340 \mathrm{~Hz} / \mathrm{nA} . B 3$, Number of spikes per $\mathrm{nA}$ was not affected by ES. The slopes were, for control, $72 \mathrm{sp} / \mathrm{nA} ; \mathrm{ES}, 70 \mathrm{sp} / \mathrm{nA}$; and wash, $62 \mathrm{sp} / \mathrm{nA}$. $C$, Effects of ES on burst firing mode in an $\mathrm{nRt}$ neuron. $C 1$, Just-threshold bursts were evoked at holding potentials of -80 (left $)$ and $-90 \mathrm{mV}($ right $)$. ES $(\square, 600 \mu \mathrm{M})$ caused a reversible $10 \mathrm{msec}$ increase from control in latency to burst at $-80 \mathrm{mV}$, and a longer increase $(47 \mathrm{msec})$ at $-90 \mathrm{mV}$. Same neuron as in Figure $1 B$. C2, Frequency versus time plots for bursts in control $(\square)$, ES $(\square)$, and wash $(\triangle)$. Neither the temporal shape nor the intraburst frequencies were affected by ES, although the delayed onset is clearly seen. The burst in ES at $-90 \mathrm{mV}$ continued upon termination of the stimulus, and its shape was the same as in control. $D$, LTS threshold is increased in ES. Brief ( 2 msec) intracellular current injections with incrementing intensities were applied to another $\mathrm{nRt}$ neuron held at $-80 \mathrm{mV}$. Four responses to stimuli near threshold are shown in control, ES $(700 \mu \mathrm{M})$, and wash. The threshold for an active response in control was $1.0 \mathrm{pC}(500 \mathrm{pA} \times 2 \mathrm{msec})$, and $1.2 \mathrm{pC}$ evoked a nearly full-size LTS. In ES, $1.0 \mathrm{pC}$ was subthreshold, and $1.2 \mathrm{pC}$ evoked only a small active response. These effects were reversible (Wash).
} 


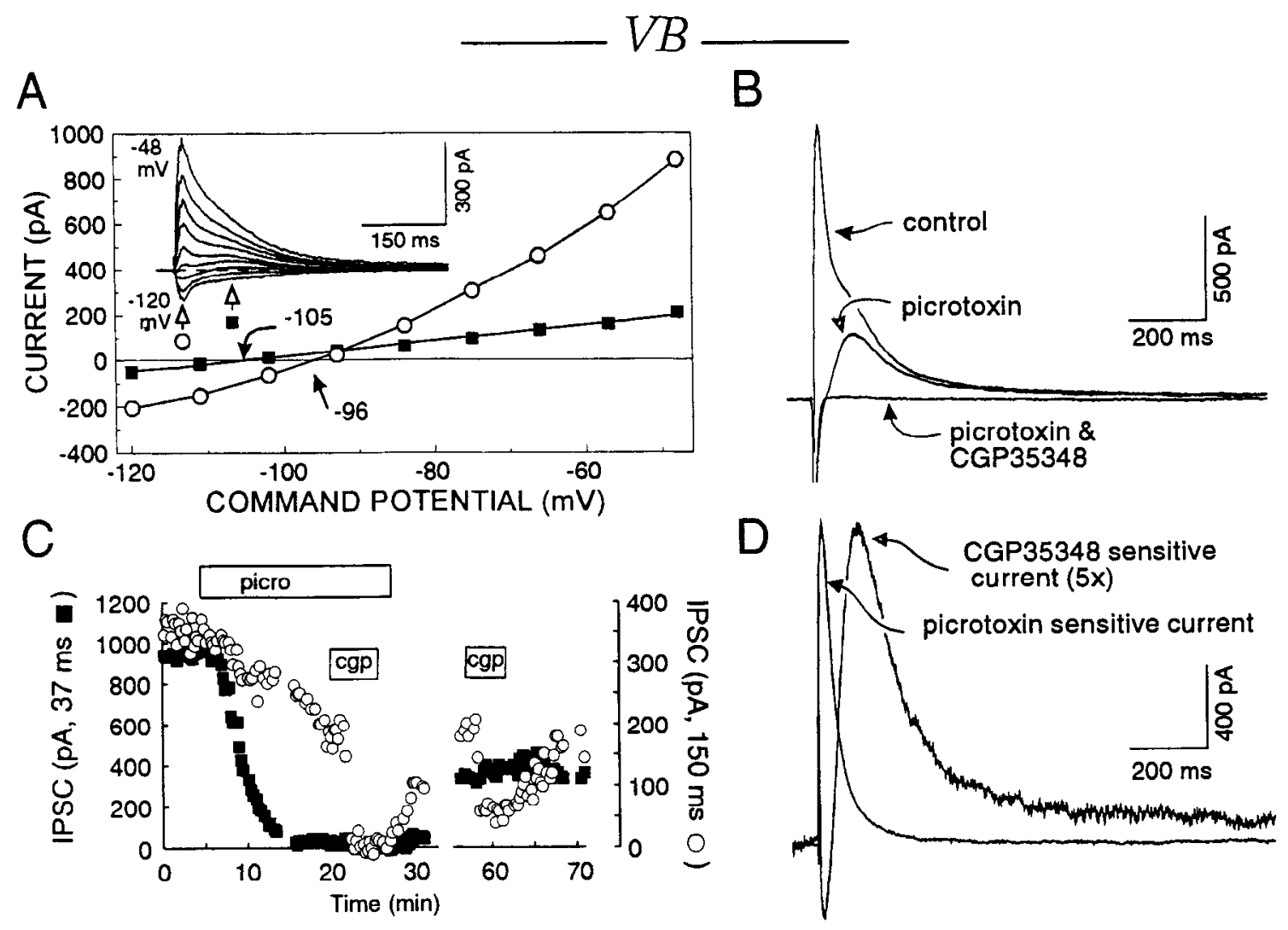

Figure 4. IPSCs in voltage-clamped VB neurons, evoked by stimulation of $\mathrm{nRt} . A$, Synaptic currents at holding potentials between - 120 and $-48 \mathrm{mV}$ evoked by $250 \mu \mathrm{A}, 40 \mu \mathrm{sec}$ extracellular stimuli applied to adjacent $\mathrm{nRt}$. The evoked current had an early component (o) peaking around $20 \mathrm{msec}$, and a late component peaking around $100 \mathrm{msec}(\square)$. Note that the current evoked at $-102 \mathrm{mV}$ (third trace from the bottom), had an early inward current followed by a later outward component. The late response reversed at $-105 \mathrm{mV}$, and is linear with a slope of $5.7 \mathrm{nS}$, while the early response showed outward rectification, a reversal of $-96 \mathrm{mV}$, and a slope (at the reversal potential) of $12 \mathrm{nS} . B$, Pharmacology of evoked inhibitory synaptic currents in relay cells. A VB neuron was voltage clamped to $-50 \mathrm{mV}$, and synaptic responses evoked by a $80 \mu \mathrm{sec}, 200 \mu \mathrm{A}$ $\mathrm{nRt}$ stimulation. In control, the evoked response consisted of an outward current that inactivated with two decay phases. Picrotoxin (70 $\mu \mathrm{M}$ ) abolished the early outward current and revealed a short-latency inward current (truncated in this trace), but spared the late component of the current that had a slow onset (peak $110 \mathrm{msec}$ ) and slow decay. This slow outward current was completely abolished by $200 \mu \mathrm{M}$ CGP35348, but the inward excitatory current remained. The traces shown are the average \pm SEM from 10 individual traces in each condition. $C$, Time course, reversibility, and repeatability of the CGP35348 block. Early currents (D) were measured at a latency of $37 \mathrm{msec}$ from the stimulus, so that contamination by the EPSC would be minimized. Late currents $(0)$ were measured at $150 \mathrm{msec}$, so that contamination by the early, picrotoxinsensitive current (see $D$ ) was minimized. Picrotoxin (picro) caused a slow onset and partially reversible blockade of mainly the early component, while repeated applications of CGP35348 (cgp) reversibly blocked the late component, but did not affect the early IPSC (see second cgp application). The GABA $\mathrm{B}_{\mathrm{B}}$ component gradually ran down during this experiment. $D$, IPSC components blocked by picrotoxin and CGP35348. The late component has been scaled up fivefold to accentuate the late decay phase. The picrotoxin-sensitive current decayed with a time constant of 30 msec, while the CGP35348-sensitive current decay showed a biphasic time course with time constants of 77 and 314 msec. A small EPSC component is shown in the CGP35348-sensitive trace and is probably the result of imperfect subtraction.

overcome the membrane active transport processes. Similar deviations from expected $E_{\mathrm{C}}$ have been seen in hippocampal (Huguenard and Alger, 1986; Zhang et al., 1991) and neocortical pyramidal cells (Fukuda et al., 1993). These deviations are initially small in hippocampal and neocortical slices from young rats and increase during development as the $\mathrm{Cl}^{-}$pump becomes more functional (Zhang et al., 1991; Fukuda et al., 1993). In several experiments we attempted to overload the $\mathrm{Cl}^{-}$extrusion system by using higher pipette $\mathrm{Cl}^{-}$concentrations. Experiments with $30 \mathrm{~mm}, 60 \mathrm{~mm}$, and $135 \mathrm{~mm}$ produced similar results. In a few VB cells, immediately after breaking into whole-cell recording mode with pipettes containing high $\left[\mathrm{Cl}^{-}\right]$, depolarizing responses or biphasic depolarizing-hyperpolarizing responses were obtained by $\mathrm{nRt}$ stimulation (Fig. $5 \boldsymbol{A}-C$ ). Even in these experiments, when the pipette access resistance increased soon after break-in, the depolarizing responses were rapidly inverted to hyperpolarizing ones (e.g., note the synaptic component in- dicated by asterisks in traces 1 and 5 of Fig. $5 A$ ), indicating that in a matter of less than a minute, relay cells are able to change their $\mathrm{Cl}^{-}$reversal potential by several tens of millivolts. As a consequence of this quite negative value for $E_{\mathrm{Cl}}, \mathrm{GABA}_{\mathrm{A}}$-mediated IPSPs would produce larger hyperpolarizations that would deinactivate more T-current channels (Coulter et al., 1989c), and thus potentially lead to rebound LTSs.

The early $\mathrm{GABA}_{\mathrm{A}}$ component could often be resolved into individual peaks (Fig. 6A; see also inset of Fig. 10) that occurred with a frequency of $300-700 \mathrm{~Hz}$, a value very similar to the frequency of spikes during bursts in nRt neurons (compare Fig. $3 C$ ). In contrast to hippocampal neurons, where only more intense stimuli evoke late $\left(\mathrm{GABA}_{\mathrm{B}}\right.$-mediated) IPSPs (Dutar and Nicoll, 1988), the two components of IPSPs in relay cells were elicited at the same threshold stimulus intensity and both were enhanced as the stimulus was increased (Fig. $6 B$ ). Normalized traces indicate that low- and high-intensity stimuli produced 
the same relative amplitudes of $\mathrm{GABA}_{\mathrm{A}}$ and $\mathrm{GABA}_{\mathrm{B}}$ responses (Fig. 6B, inset), and the amplitudes of the two events were highly correlated (Fig. $6 D$ ), with $r^{2}$ of $0.94 \pm 0.04(n=7)$. This is not too surprising since the resting potential of $\mathrm{nRt}$ neurons in the slice tended to be quite hyperpolarized $(<-80 \mathrm{mV})$, so that the cells were in burst firing mode and even threshold extracellular excitation would evoke a high-frequency burst and thus a potent IPSP. In seven cells the average linear regression slope was 0.20 \pm 0.085 , indicating that $\mathrm{GABA}_{\mathrm{B}}$ current was about $20 \%$ of the $\mathrm{GABA}_{\mathrm{A}}$ component. In some cells, strong stimuli evoked a prominent short-latency $(100 \mathrm{msec})$, secondary $\mathrm{GABA}_{\mathrm{A}}$-mediated response (Fig. $5 A ; C,{ }^{* *}$ ) that was probably due to intra$\mathrm{nRt}$ mechanisms and not recurrent excitation since it persisted in the presence of excitatory amino acid neurotransmitter blockade (Fig. $5 C,{ }^{* *}$ ) and unit activity at this latency was sometimes observed in nRt (e.g., Fig. $9 C,{ }^{*}$ ).

Since the evoked IPSPs in VB neurons were thus dependent on bursting in $\mathrm{nRt}$ neurons, ethosuximide, by reducing the burst probability of $n R t$ cells, should reduce the relay cell IPSP(C) evoked by $n R t$ stimulation. Both $\mathrm{GABA}_{\mathrm{A}}$ and $\mathrm{GABA}_{\mathrm{B}}$ components in VB evoked with relatively strong $\mathrm{nRt}$ stimulation ( $\sim 60 \%$ of maximal response) were slightly reduced by ES ( 700 $\mu \mathrm{M}$, not shown). On the other hand, the effect of ES was more dramatic under conditions of threshold stimulation that evoked an initial burst of fast IPSPs followed by a small, late GABA response (Fig. $7 A$, control). As the drug washed in (Fig. $7 B$ ) there was a disappearance of the late $\mathrm{GABA}_{B}$ event $(\nabla)$ as well

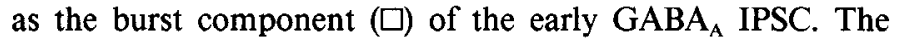
earliest component of the response ( $\square$ ), possibly due to orthodromic activation of $\mathrm{nRt}$ axons, was unaffected by ES in this cell (Fig. $7 A, B$ ), indicating that there was not a major effect on postsynaptic responsiveness (Coulter et al., 1990b). nRt neuron intrinsic excitability, studied under similar conditions of threshold stimulation, was very similarly affected by ES (Fig. $7 \mathrm{C}$ ). In this case, a burst response was obtained by stimulation in internal capsule directly adjacent to the intracellular recording in nRt. As ES washed in the probability of obtaining burst responses was reduced; more and more failures occurred until there were no bursts (traces immediately after 3 in Fig. $7 \mathrm{C}$ ). Washout of the drug restored burst probability to control levels. It is interesting to note that, although the likelihood of bursts was dramatically reduced by ES in this experiment, the shape of the burst was relatively unaffected, as shown in the control (1), ES (3), and wash (4) traces in Figure 7D. This is more clearly seen in the intraburst frequency/spike frequency plots (Fig. $7 E$ ), where bursts 1,3 , and 4 are plotted and essentially overlap in their time course. This change in $\mathrm{nRt}$ responsiveness was not due to changes in excitatory drive, since the excitatory postsynaptic current (EPSC) in nRt neurons was unaffected by ES (Fig. $7 F)$.

\section{Components of an intrathalamic oscillation}

Within the horizontal slice there exists circuitry that can support intrathalamic oscillation, based on reciprocal connectivity between $\mathrm{nRt}$ and VB (Fig. 8A, inset). Stimulation of nRt (St.) directly activates $n R t$ cells as well as two sets of excitatory fibers that innervate $\mathrm{nRt}$, the corticothalamic fibers (synapse 1), and the thalamocortical fibers (synapse 2). The potent inhibitory response in VB cells (Fig. 8A) then results from feedforward inhibition (synapse 3), which is more potent than the monosynaptic excitation produced by corticothalamic input (synapse 4). The EPSP resulting from activation of synapse 4 (e.g., arrow

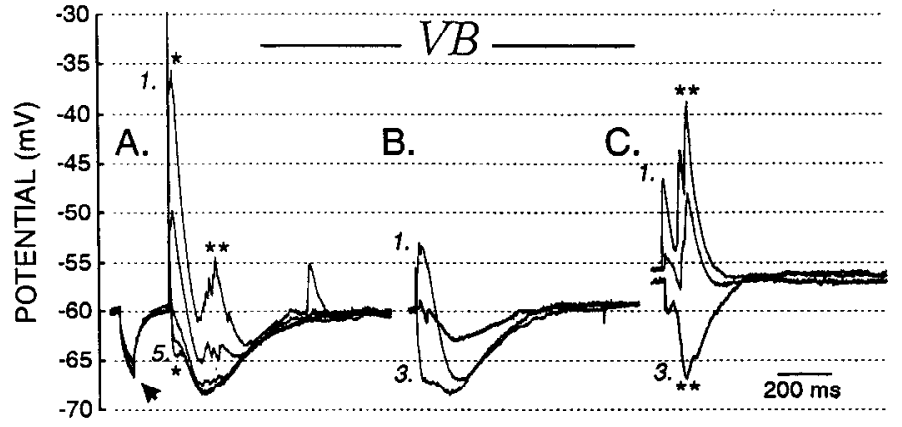

Figure 5. Rapid Cl- extrusion in relay neurons. Evoked IPSPs in three relay neurons. IPSPs were initially depolarizing, and then rapidly inverted to hyperpolarizing responses. In each cell the responses were evoked every $15 \mathrm{sec}$. $A$, Neuron with an initial depolarizing response to nearly $-35 \mathrm{mV}\left(1,{ }^{*}\right)$. One minute later (trace 5), same stimulus evoked a hyperpolarizing response to $-65 \mathrm{mV}\left(5,{ }^{*}\right)$. The calculated intracellular $\left[\mathrm{Cl}^{-}\right]$for trace 1 was $>27 \mathrm{~mm}$, and for trace 5 was $<9 \mathrm{~mm}$. Alteration in the response to an intracellular current injection (arrow) was due to resealing of the recording electrode and resultant bridge imbalance rather than a change in input resistance. Upon break-in, initial access resistance was $11 \mathrm{M} \Omega$ and increased to $60 \mathrm{M} \Omega$ by trace 5 . Similar increases in access resistance occurred in cells $B$ and $C$ (not shown). $B$, Neuron generated an early "IPSP" that inverted within 30 sec. $C$, Responses obtained with $10 \mu \mathrm{M}$ CNQX and $25 \mu \mathrm{M}$ D-AP5 in the bath to block excitatory transmission. A second burst IPSP occurs approximately $100 \mathrm{msec}$ from the stimulus in $A$ and $C\left({ }^{* *}\right)$. Both primary and secondary IPSPs invert within $30 \mathrm{sec}$. Pipette $\left[\mathrm{Cl}^{-}\right]$was $60 \mathrm{~mm}$ for cell $A$ and $135 \mathrm{~mm}$ for cells $B$ and $C$.

in Fig. 8A) was always subthreshold for spike generation. The feedforward IPSP was robust and could sometimes lead to generation of a rebound $\mathrm{Ca}^{2+}$-dependent burst (Fig. $8 A{ }^{* * *} ; B$ ). The IPSPs were biphasic with early and late components mediated by $\mathrm{GABA}_{A}$ and $\mathrm{GABA}_{B}$ receptors, as shown for the underlying IPSCs in Figure 4. Because there was a prominent $\mathrm{GABA}_{\mathrm{B}}$ component (Fig. 8A, ${ }^{* *}$ ), with an underlying slow inactivation process (Fig. $4 D$ ), each IPSP could maintain the membrane potential at a hyperpolarized level for several hundred milliseconds. The hyperpolarization extended into the range of T-channel deinactivation for these cells (more negative than $-60 \mathrm{mV}$; Coulter et al., 1989c), so that these channels could become primed by the IPSP. Upon decay of the inhibitory response, the membrane potential approached the activation range for $I_{\mathrm{T}}$ (positive to $-70 \mathrm{mV}$; Coulter et al., 1989c), and a regenerative LTS or burst (Fig. $8 A,{ }^{* * *}$ ) was triggered. Since relay cells are reciprocally connected to sectors within nRt (Jones, 1985; Mitrofanis and Guillery, 1993), the action potentials triggered by the VB burst should produce EPSPs in nRt neurons (synapse 2), possibly leading to generation of burst responses similar to those seen in Figure $7 D$. An nRt neuron burst such as this would evoke late IPSPs in relay neurons (synapse 3). We found that such "secondary" IPSPs were a common phenomcnon in rat horizontal thalamic slices. They occurred with an inter-IPSP interval of $373 \pm 65 \mathrm{msec}(n=38)$, and sometimes fell at the same latencies as the rebound burst evoked on other trials (Fig. 8B, arrows). It appears that these secondary IPSPs can, thus, block generation of rebound bursts and dampen the circuit-based oscillation. Oscillations with underlying IPSPs could be sustained for up to seven cycles lasting over $1200 \mathrm{msec}$.

The secondary IPSPS could have resulted from intrinsic processes within $\mathrm{nRt}$, whose neurons can, under certain conditions, generate a self-sustained oscillation or repetitive bursts (Avanzini et al., 1989; McCormick and Wang, 1991). This is unlikely, 

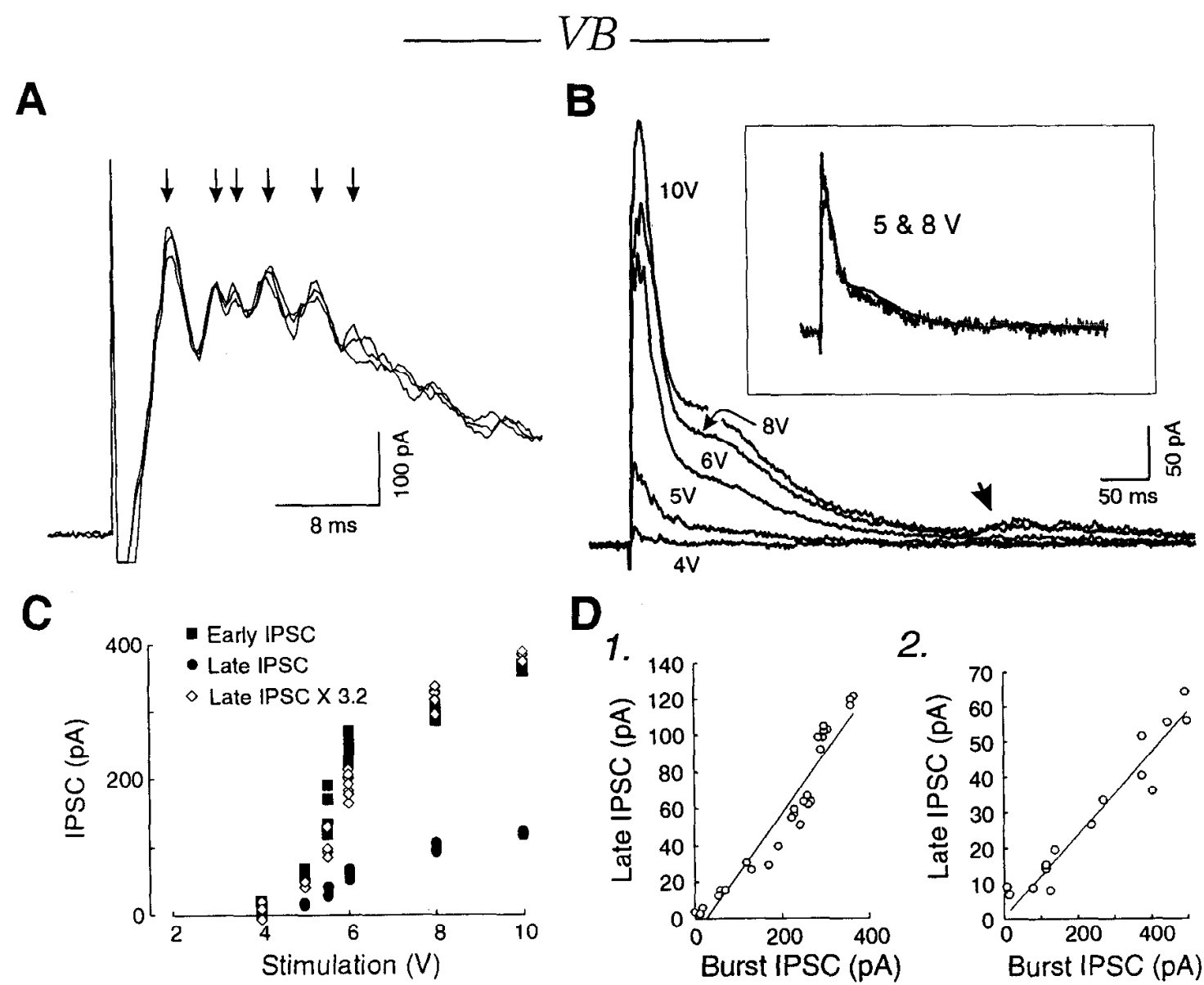

2.

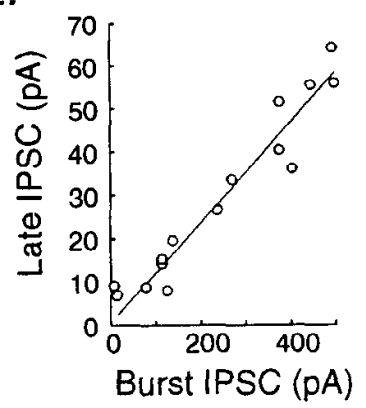

Figure 6. Relationship between $\mathrm{GABA}_{\mathrm{A}}$ and $\mathrm{GABA}_{\mathrm{B}}$ components of evoked $\mathrm{nRt}$ IPSCs. $A$, Three consecutive voltage-clamp traces obtained in a VB neuron at a holding potential of $-50 \mathrm{mV}$. Several peaks are resolved in each sweep (arrows). The intervals between peaks varied between 1.5 and $3.6 \mathrm{msec}$. $B$, Intensity series for evoked responses. At threshold (4 V) an early outward current is evoked followed by a small late phase. Increasing the stimulus strength increased the amplitude of the early, short latency IPSC peak but also increased the late second component that became prominent with stimuli greater than $5 \mathrm{~V}$. Inset, The $5 \mathrm{~V}$ (thicker line) and $8 \mathrm{~V}$ responses are normalized to show that the relative sizes of the early and late components are independent of stimulus intensity. Arrowhead, secondary IPSC. $C$, Input-output function for the evoked responses in $B$. The late $(100 \mathrm{msec})$ IPSC was always smaller than the early $(20 \mathrm{msec})$ component, but both varied with stimulus strength. The amplitude of the late component, when scaled by 3.2 times $(\diamond)$ closely matches that of the early component at each stimulus strength. $D$, Plot of late IPSC amplitude versus amplitude of the early (burst) IPSC in two different cells. $D 1$, Same cell as $B$ and $C$; slope $=0.329, r^{2}=0.925$. D2, Another cell with slope $=0.116, r^{2}=0.921$.

however, because the initiation and maintenance of sustained oscillations such as those of Figure $8 B$ were dependent on intact excitatory neurotransmission $(n=7$; Fig. $8 C 1)$. The source of the excitation must be the relay neurons (synapse 2 ) since all nRt neurons are GABAergic (Houser et al., 1980; Jones, 1985). Blockade of NMDA- and non-NMDA-mediated excitatory responses with CNQX and D-AP5 (Fig. 8C1) caused a large reduction and/or blockade of the primary $\left(\mathrm{GABA}_{\mathrm{A}}\right.$ and $\left.\mathrm{GABA}_{\mathrm{B}}\right)$ and secondary IPSPs, and increasing the stimulus strength (thick line in Fig. $8 C 1$ ) partially restored only the primary but not the secondary IPSPs. Thus, the secondary IPSPs were dependent on recurrent excitation of $n R t$. Furthermore, extracellular stimulation in $\mathrm{nRt}$ must activate traversing excitatory corticothalamic and thalamocortical fibers which then secondarily activate several $\mathrm{nRt}$ neurons (synapses 1 and 2). Without this divergent excitation, the intra-nRt stimulus is much weaker, indicating that direct electrical stimulation accounts for only a small portion of the activation of nRt cells under these conditions. Blockade of only the NMDA receptor-mediated responses with D-AP5 produced a rapid but only partial $(\sim 20 \%)$ decrease in the evoked primary IPSP (Fig. 8C2) and blockade of the secondary IPSP. However, increasing the stimulus strength (thick line in Fig. $8 \mathrm{C3}$ ) resulted in a primary IPSP larger than control but incomplete restoration of secondary event. Thus, synapses 1 and 2 are probably mediated by both NMDA and non-NMDA receptors (see Discussion).

Reduction in the excitatory drive onto $\mathrm{nRt}$ by CNQX and AP5 did not affect the essential features of the IPSP. Prominent $\mathrm{GABA}_{\mathrm{A}}$ and $\mathrm{GABA}_{\mathrm{B}}$ components were present after blockade of NMDA receptors (Fig. $8 C 2$ ) or blockade of both NMDAand non-NMDA-mediated responses (Fig. $8 C 1, D 2$ ). The large increase in the threshold to evoke an IPSP can be seen in Figure $8 D 2$, where the control threshold was $150 \mu \mathrm{A}$, and increased to $500 \mu \mathrm{A}$ in AP5 and CNQX. Increasing the stimulus strength restored the primary IPSPs to near control levels but did not overcome the block of the secondary IPSP (Fig. $8 C 1, D 2$ ). The wash-in of excitatory amino acid blockers produced a biphasic effect, probably due to the different tissue access of AP5 and 

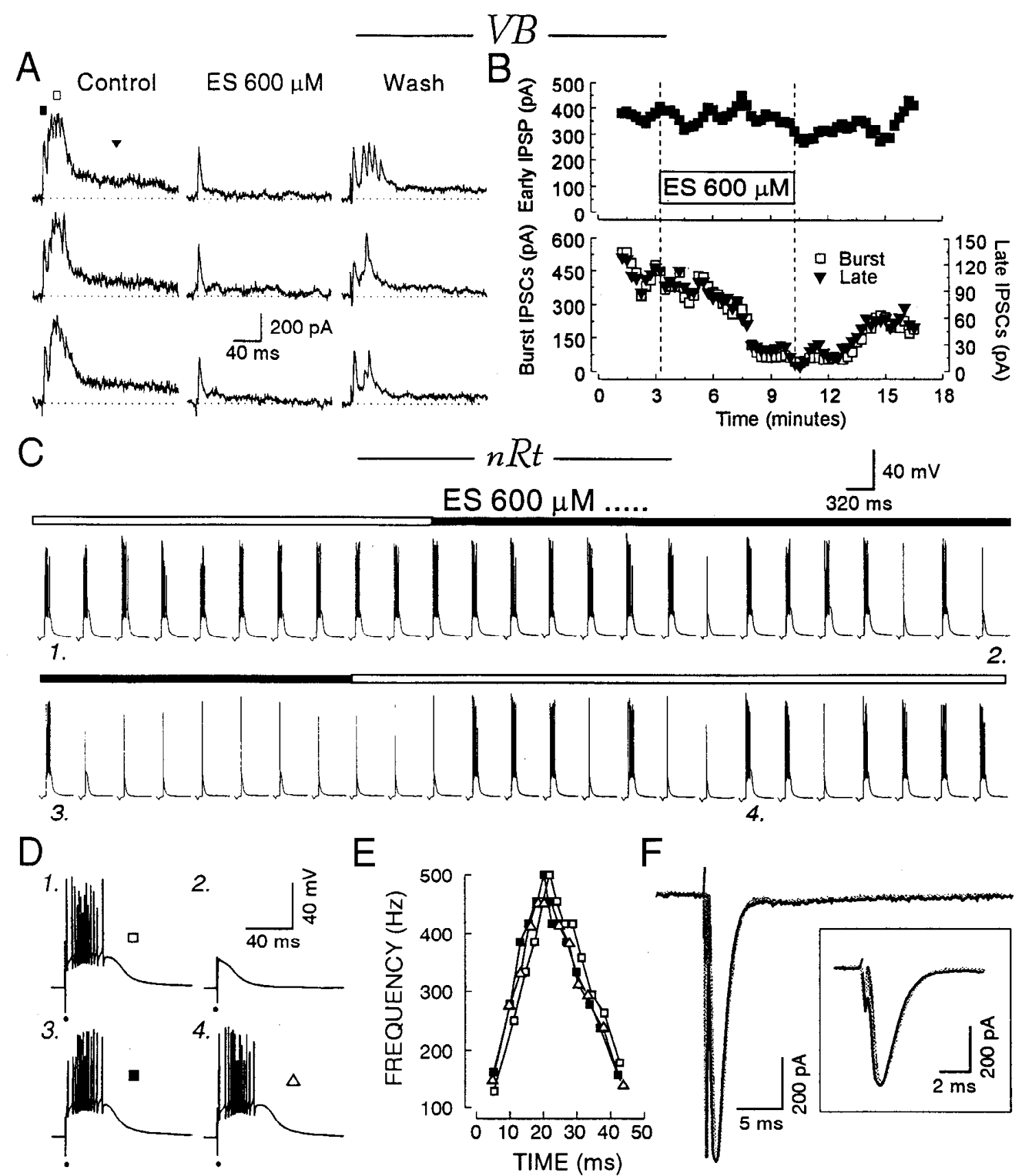

Figure 7. ES reduces burst probability of nRt cells and their inhibitory output. $A$, Three components of burst response in a VB neuron evoked by $40 \mu \mathrm{sec}, 200 \mu \mathrm{A}$ stimuli in nRt include a short-latency $(2.5 \mathrm{msec})$ monophasic IPSC ( $\square$ ), a later burst of IPSCs (measured at 20 msec latency, $\square$ ), and a very late, slowly decaying component (measured at $100 \mathrm{msec}, \boldsymbol{\nabla})$. ES reversibly blocked the later two phases, while leaving the earliest component intact. B:Upper graph, The early IPSC was unaffected by ES (applied at times indicated by vertical lines). Lower graph, Amplitudes of the burst and late response were correlated (note different scale on right for late IPSC), and both were decreased in a reversible manner by ES. $C$, ES reduces burst probability in an $\mathrm{nRt}$ neuron. Stimuli $(500 \mu \mathrm{A}, 140 \mu \mathrm{sec})$ were applied every $15 \mathrm{sec}$ to the internal capsule and burst responses were consistently evoked in an nRt neuron. As ES washed in, the burst probability was dramatically decreased, although bursts were occasionally still elicited (see trace 3). Upon washout of ES the burst response returned. D, Burst responses are similar in control (I), ES (3), and wash (4). 2, An example of an EPSC that did not evoke a burst in ES. $E$, Intraburst spike frequencies for the traces in $D$ show that the burst was totally unaffected by ES ( $\square$. F . Excitatory synaptic response evoked by stimulation of the internal capsule was not affected by ES. Control and ES traces are superimposed. Inset shows the EPSCs at a faster sweep speed. Same cell as in Figure $1 C$.

CNQX. The more water-soluble AP5 should equilibrate with the tissue much more rapidly than CNQX. Thus, the time course of wash-in provides information about the likely contributions of NMDA and non-NMDA receptors to this evoked response. Normally, there was a rapid (complete in less than $30 \mathrm{sec}$ ) 20 $25 \%$ blockadc in the IPSP followed by a more gradual (minutes) reduction in the IPSP (not shown).

\section{$T$-channel blockers inhibit intrathalamic oscillations}

The slight increase in the threshold for burst generation produced by succinimides (Fig. 3) should dampen the intrathalamic oscillation, which is dependent on burst firing in nRt cells (to produce potent IPSPs; comparc Fig. 6) and rebound burst firing in VB (compare Fig. 8A). The following experiments tested that 


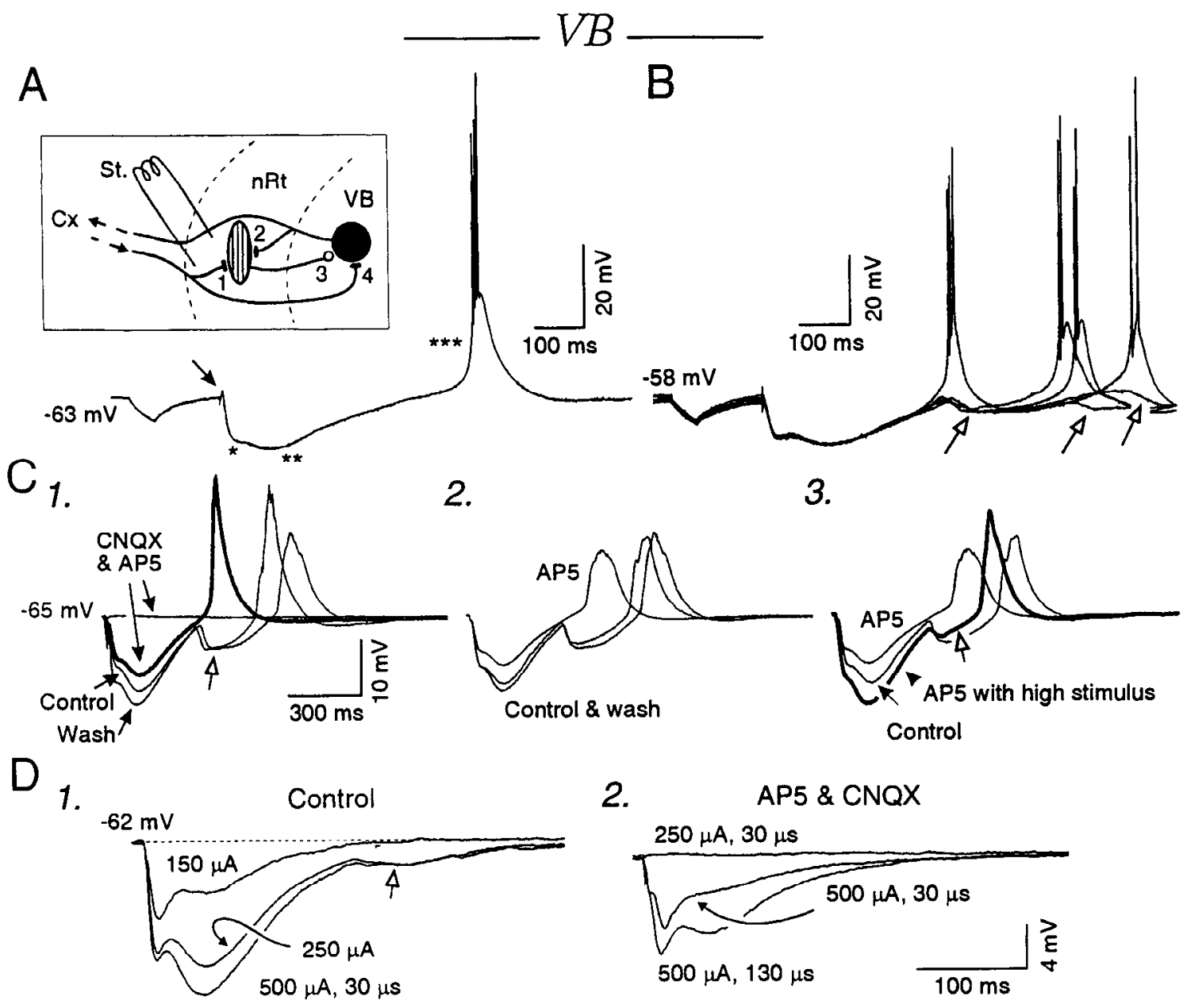

Figure 8. Components of an intrathalamic rebound oscillation. $A$, A long-lasting IPSP is evoked by a single shock ( $200 \mu \mathrm{A}, 40 \mu \mathrm{sec})$ to $\mathrm{nRt}$. The IPSP has hyperpolarizing early $\left(^{*}\right)$ and late $\left(^{* *}\right)$ components that deinactivate T-channels so that a rebound $\mathrm{Ca}^{2+}$-dependent burst $\left(^{* * *}\right)$ is triggered upon decay of the IPSP. Small EPSP (arrowhead) evoked by nRt stimulation is due to activation of corticothalamic fibers (see inset). Inset, Schematic of the intrathalamic circuit. A stimulating electrode (St.) in $\mathrm{nRt}$ directly activates $\mathrm{nRt}$ cells, as well as corticothalamic fibers (synapse 1 and 4 ) and thalamocortical fibers (synapse 2), which indirectly activate $\mathrm{nRt}$ cells. The output of nRt evokes IPSPs on VB cells (synapse 3). B, In another cell, nRt stimuli evoke repetitive IPSPs (open arrows) that sometimes block the generation of secondary bursts. At times indicated by open arrows either a rebound burst or a secondary IPSP occurs. $C$, Excitatory neurotransmission is necessary for secondary IPSPs. $C 1$, Stimulus evokes a large IPSP with $\mathrm{GABA}_{\mathrm{A}}$ and $\mathrm{GABA}_{\mathrm{B}}$ components and a secondary IPSP (open arrow). The addition of $10 \mu \mathrm{M}$ CNQX and $25 \mu \mathrm{M}$ D-AP5 reversibly abolishes all IPSP components (top arrow), although primary early and late IPSPs could be evoked with higher stimulus intensities (thick line, $500 \mu \mathrm{A}, 230$ $\mu \mathrm{sec}$, compared to $250 \mu \mathrm{A}, 30 \mu \mathrm{sec}$ in control). Each sweep is the average of three to eight trials. $C 2$, NMDA receptor blockade (with bath application of $25 \mu \mathrm{M}$ D-AP5) reduces GABA $_{A}$ and GABA $A_{B}$ components, blocks the secondary IPSP, and speeds the onset of the rebound LTS. C3, Increasing the stimulus strength (from 250 to $500 \mu \mathrm{A}$ ) in AP5 (thick trace and arrowhead) increases the $\mathrm{GABA}_{\mathrm{A}}$ and $\mathrm{GABA}_{\mathrm{B}}$ components to greater than control levels, and partially restores the secondary IPSP (open arrow). DI, Control: evoked IPSPs at three stimulus intensities in another VB neuron with less prominent secondary IPSPs than the cell of $C$. D2, CNQX and AP5 block all components evoked by the $250 \mu \mathrm{A}$ stimulation, and dramatically reduce the $\mathrm{GABA}_{\mathrm{A}}$ and $\mathrm{GABA}_{\mathrm{B}}$ components evoked with $500 \mu \mathrm{A}$. When the stimulus duration was increased to $130 \mu \mathrm{sec}$ (maximal), both components were increased, but not to control levels.

hypothesis. We examined the effect of ES on intrathalamic oscillations evoked in slices from young animals (P10-P19), where they were most readily triggered and more sustained, perhaps because of the preservation of more of the intrathalamic circuitry in $400 \mu \mathrm{m}$ slices of smaller brains. We assumed that the extracellular stimulus in $\mathrm{nRt}$ would activate many $\mathrm{nRt}$ neurons that would have intact reciprocal connections with several relay cells. Extracellular multiunit recordings in nRt and VB showed that the oscillations were a network property and were variable from trial to trial (note the differences in three consecutive control traces in Fig. 9A). In the presence of ES, the oscillation was markedly shortened to one to two cycles compared to three to four cycles in control and wash (Fig. 9A). To quantify the ES effects we measured the total duration and total number of spikes in each nRt-evoked oscillation. Both measures showed clear reductions by ES. In the example shown in Figure $9 B$, total spikes decreased from 16 in control to 10 in $600 \mu \mathrm{M}$ ES and back to 16 in wash, while oscillation duration decreased from $1050 \mathrm{msec}$ to $900 \mathrm{msec}$. This effect was concentration dependent since $300 \mu \mathrm{M}$ ES (Fig. 9B) and $150 \mu \mathrm{M}$ ES (not shown) had progressively smaller effects than those seen with $600 \mu \mathrm{M}$. On average, $600 \mu \mathrm{M}$ ES reduced the total spikes by $50 \pm 27 \%$ and oscillation duration by $33 \pm 27 \%(n-7)$.

Recently, an intrageniculate oscillation resembling spindle activity has been described in ferret thalamic slices (von Krosigk et al., 1993). Interestingly, the spindle rhythm can be converted 

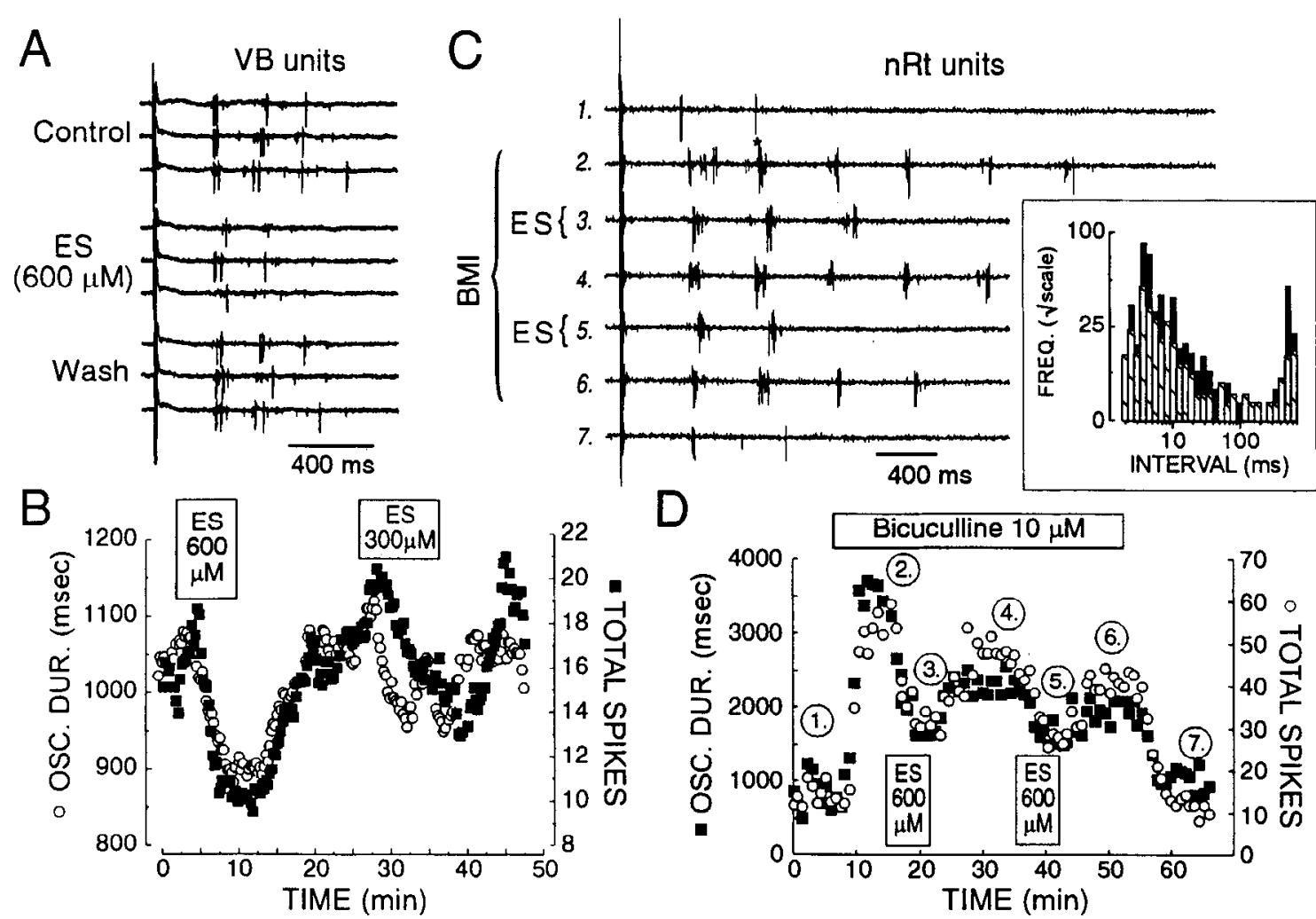

Figure 9. Ethosuximide dampens rhythmic oscillations involving nRt and VB. $A$, A multiunit extracellular recording from VB. Three consecutive traces are shown for each condition. The oscillation evoked by an extracellular stimulus in $\mathrm{nRt}$ (in $A-D$ ) lasts for three or four cycles in control, and is reversibly reduced to two less robust cycles with fewer spikes by ES. The effects of ES on two measures of oscillation are shown in $B$. Both the duration of oscillation (OSC. DUR., O; measured from the stimulus to the last spike) and total number of spikes ( $\mathrm{C}$, note different scales) were reduced by $600 \mu \mathrm{M} \mathrm{ES}$, and lesser effects were produced by $300 \mu \mathrm{M}$ ES. Each point is the running average of three consecutive trials. $C$, Multiunit recordings obtained from nRt. Bicuculline methiodide $(B M I, 10 \mu \mathrm{M})$ transforms the abortive oscillation in control (1) to a sustained oscillation lasting at least six cycles (2) Ethosuximide $(E S, 600 \mu \mathrm{M})$ reversibly, and repeatedly dampens the sustained oscillation (3 and 5$)$. The increased oscillation induced by BMI is completely reversible (7). The inset shows a interval histogram from the nRt unit recording. The black bars are the data from 10 sweeps in condition 2, while the hatched bars are from condition 3. The peaks (number of intervals) at $3.4 \mathrm{msec}(295 \mathrm{~Hz}$ ) were 89 , 51 , and 97 in control, ES, and wash, respectively (45\% reduction), while the corresponding peaks at $470 \mathrm{msec}(2.1 \mathrm{~Hz})$ were 52,14 , and $34(67 \%$ reduction). Not shown are histograms for the repeated ES applications or wash conditions (4-6), whose distributions were indistinguishable from those in the inset, except that the peak at $3.4 \mathrm{msec}$ never returned to the initial BMI levels. $D$, Time series for the experiment in $C$. BMI initially increased the oscillation duration ( $\square$ ) about fourfold and the number of spikes (o) about sixfold. ES rapidly and reversibly opposes this effect.

to a slower, absence-like rhythm by blocking $\mathrm{GABA}_{\mathrm{A}}$ receptors. We never saw spindle-like activity in rat somatosensory thalamus, either evoked or spontaneous. This is likely due to the

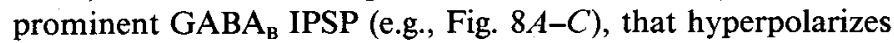
relay cells for several hundred milliseconds and thus prevents their excitation during the short interspindle period $(120 \mathrm{msec})$. In our preparation blockade of $\mathrm{GABA}_{\mathrm{A}}$ receptors with bicuculline methiodide (BMI; $10 \mu \mathrm{M}$ ) did not affect the frequency of the intrathalamic oscillation, but it did enhance their strength and duration $(n=4)$, and thus increased the ability of the thalamic slice to sustain slow (2-3 Hz) abscncc-likc rhythms. In the example of Figure $9 C$, both the total number of spikes and oscillation duration increased by more than fourfold. Furthermore, $600 \mu \mathrm{M}$ ES reversibly reduced the enhanced oscillation. Interspike interval analysis showed that there were two peaks, one near $470 \mathrm{msec}$ and a second near $3 \mathrm{msec}$, representing the inter- and intra-spike burst intervals, respectively. ES caused a large $(67 \%)$ reduction in the peak near $470 \mathrm{msec}$ and a smaller reduction $(45 \%)$ reduction in the peak near $3 \mathrm{msec}$, indicating that there was a less effect on the nRt neuron bursts themselves than there was on the interval between bursts. This effect of
$\mathrm{BMI}$ is presumably due to an enhancement of $\mathrm{GABA}_{\mathrm{B}}$ responses in $\mathrm{VB}$ that results from a disinhibition in $\mathrm{nRt}$. Application of $\mathrm{BMI}$ to the bath or local perfusion in $\mathrm{nRt}$ has been shown to

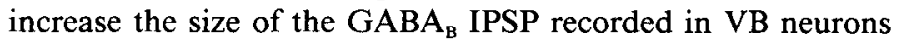
(Huguenard and Prince, 1994).

Intracellular recordings in VB during intrathalamic oscillations revealed repetitive bursts of IPSCs throughout the oscillation. In voltage-clamp recordings, the oscillation was marked by periodic bursts of IPSC's with decrementing amplitudes ( $n=$ 3 ; Fig. 10). Note that there were occasional dropouts of IPSCs in the middle of an oscillatory cycle. In the example shown in Figure 10, traces 4 and 5 (from bottom) are missing the third IPSCs (*) and traces 1 and 2 are missing the fourth IPSP $\left({ }^{* *}\right)$. Often, the late oscillatory IPSCs could be resolved into individual high-frequency peaks (lower inset) and thus were likely to be the result of only a few nRt neurons firing as the oscillation dwindled. When $600 \mu \mathrm{M}$ ES was bath applied, the oscillations were markedly dampened (from five or six cycles down to two), and the size of the primary and secondary bursts reduced (not shown). The anti-oscillatory effect was reversible upon removal of ES from the bath. 


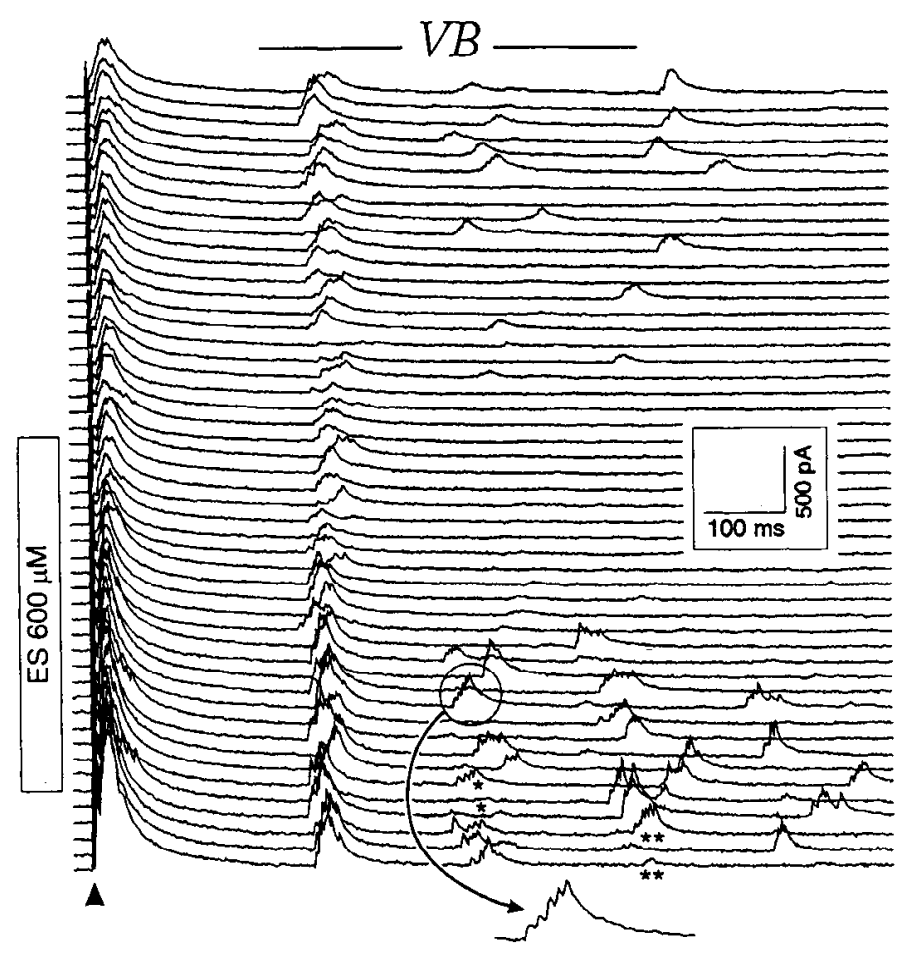

Figure 10. Reduction in intrathalamic rhythmicity by ES is accompanied by decrementing amplitude of oscillatory IPSCs. A VB neuron was voltage clamped at $-50 \mathrm{mV}$, and a single shock $(250 \mu \mathrm{A}, 100 \mu \mathrm{sec})$ was applied to nRt every $15 \mathrm{sec}$. The lowest of the 50 traces shown is control, and successive traces are displayed above. In control, the single shock evokes an initial outward IPSC followed by a second smaller event 275 msec later, with subsequent events of various amplitudes occurring approximately every $200-250 \mathrm{msec}$. In this cell three to seven repetitive responses were obtained from each stimulus. Note that the third $\left(^{*}\right)$ or fourth $\left({ }^{* *}\right)$ response was occasionally absent, but another response occurred where fourth or fifth responses normally would fall. As ES washed in the number of oscillatory cycles decreased to two Upon washout of the drug, the oscillation again increased to four cycles. The inset shows the individual peaks that can be resolved in a secondary IPSC at faster sweep speed. In wash, IPSP amplitude was reduced compared to control and the rise times of the IPSCs were slowed due to increased series resistance, but this did not interfere with the ability to detect late secondary IPSCs.

\section{Discussion}

\section{Slow intrathalamic oscillations}

These results show that slow $(\sim 3 \mathrm{~Hz})$ network oscillations can be evoked in a reduced slice preparation containing interconnected $\mathrm{nRt}$ and VB neurons. The oscillation depends on $\mathrm{Ca}^{2+}$ dependent burst firing in both $\mathrm{nRt}$ and VB according to the following scenario. The neurons within $\mathrm{nRt}$ are relatively hyperpolarized at rest (more negative than $-70 \mathrm{mV}$ ). Thus, T-channels arc available for activation (Hugucnard and Prince, 1992a) and excitatory drive (synapses 1 and 2 or Fig. $8 A$ ), even near threshold, results in a strong burst response (e.g., Fig. $7 D$ ). This evokes robust IPSPs (synapse 3 ) in VB neurons (e.g., Fig. $8 A$ ), and these, especially through their prolonged (>200 msec) $\mathrm{GABA}_{\mathrm{B}}$ component, can hyperpolarize the relay neurons long enough to deinactivate many of their T-channels (cf. Coulter et al., 1989c). Upon decay of the IPSP, the membrane potential depolarizes, the threshold for LTS generation is crossed (e.g., Fig. $8 A,{ }^{* * *}$ ) and a burst with several $\mathrm{Na}^{+}$-dependent action potentials is produced. These spikes evoke EPSPs at synapse 2, which can then recruit nRt cells into the next cycle of the oscillation.

Although we have a limited number of recordings in $\mathrm{nRt}$ cells, based on these results, we can make some inferences about the postsynaptic receptors at synapses 1 and 2 . These excitatory synapses in $\mathrm{nRt}$ are apparently mediated by both non-NMDA and NMDA receptors (cf. de Curtis et al., 1989). Most of the initial excitatory drive (from intra-nRt or internal capsule stimulation) onto nRt cells appears to be non-NMDA mediated since AP5 blocks less than half of the inhibitory response in VB (e.g., Fig. 8C2). By a similar argument, at least part of the excitatory response evoked in $\mathrm{nRt}$ from by VB cell firing is non-NMDA rcceptor mediated, because the secondary IPSP could still be evoked in the presence of AP5 (Fig. 8C2). We can infer that there may also be a major NMDA component at synapse 2 since the secondary IPSP could not be restored to control levels in AP5, even with a very large primary IPSP (Fig. $8 C 3$ ) that should activate many VB neurons to fire rebound bursts as in Figure $8 A$. Thus, the train of EPSPs produced at synapse 2 by bursts of spikes in VB cells may evoke a prolonged depolarization in $\mathrm{nRt}$ cells leading to activation of an NMDA-mediated component of the composite EPSP, as the $\mathrm{Mg}^{2+}$ block of NMDA receptors is relieved (Nowak et al., 1984).

The IPSPs in VB evoked by nRt stimulation have two unique features that indirectly promote oscillatory behavior. First of all, the $\mathrm{GABA}_{\mathrm{A}}$ responses are large (up to $30 \mathrm{nS}$ ) and have a very negative reversal potential $(-94 \mathrm{mV})$. The functional implication is that even $\mathrm{GABA}_{\mathrm{A}}$-mediated IPSPs would provide sufficient hypcrpolarizing drivc to deinactive $T$-channels. If such negative $E_{\mathrm{Cl}} \mathrm{S}$ valves are common features in relay neurons of other species, then this finding is important in understanding the mechanisms underlying spindle generation, as studied in vitro in ferret thalamic slices (von Krosigk et al., 1993); individual $\mathrm{GABA}_{\mathrm{A}}$ IPSPs may provide a basis for rebound $\mathrm{Ca}^{2+}$. dependent bursts in relay cells, which then reexcite $\mathrm{nRt}$ (or the equivalent perigeniculate nucleus) to provide a higher-frequency intrathalamic oscillation than that reported here. A second unusual feature of VB IPSPs is the prominent $\mathrm{GABA}_{\mathrm{B}}$ component. Under these experimental conditions, both components of the IPSP are evoked, even at threshold. This contrasts with observations in hippocampus where higher simulation intensities are necessary to evoke $\mathrm{GABA}_{\mathrm{B}}$ responses (Dutar and Nicoll, 1988). The underlying assumption from these observations in hippocampus is that the amount of GABA released at a given synapse determines, at least in part, whether $\mathrm{GABA}_{A}$, or $\mathrm{GABA}_{\mathrm{A}}$ and $\mathrm{GABA}_{\mathrm{B}}$ receptors will be activated (see Otis and Mody, 1992; but also see Williams and Lacaille, 1992). In organotypic hippocampal cultures (Thompson and Gahwiler, 1992), GABA IPSPs were not seen with monosynaptic stimulation in the presence of D-AP5 and CNQX, and thus were dependent on excitatory neurotransmission. It may be that, in the hippocampus, a combination of non-NMDA and NMDA receptor activation of interneurons provides the type of long-lasting excitation that causes several high-frequency action potentials that would release enough GABA to activate both $\mathrm{GABA}_{A}$ and $\mathrm{GABA}_{\mathrm{B}}$ receptors. The capacity to generate high-frequency bursts of spikes is "built into" nRt neurons (Huguenard and Prince, 1992a), allowing them to release sufficient GABA onto targets in dorsal thalamus to activate both $\mathrm{GABA}_{\mathrm{A}}$ and $\mathrm{GABA}_{\mathrm{B}}$ receptors at threshold.

The slowly inactivating $G A B \Lambda_{B}$ component of IPSPs in relay neurons is likely to be an important timing mechanism for the 
intrathalamic rhythm. Because of the voltage and time dependence of $I_{\mathrm{T}}$ deinactivation (Coulter et al., 1989c), a prolonged intense hyperpolarization ensures the generation of robust rebound bursts and also primes relay neurons to fire robust $\mathrm{Ca}^{2+}$ dependent bursts when activated by corticothalamic volleys. The $\mathrm{GABA}_{\mathrm{B}}$ antagonist CGP35348 can block spike-wave activity in several animal models (Hosford et al., 1992; Liu et al., 1992; Snead, 1992), an effect that can also be produced with intrathalamic injection of the antagonist (Liu et al., 1992). Thus, thalamic $\mathrm{GABA}_{\mathrm{B}}$-mediated responses, such as those described here, are likely to be important in the generation of absence epilepsy, at least in some models. The duration of the IPSP, about $300 \mathrm{msec}$, sets up an oscillation with a frequency near 3 $\mathrm{Hz}$, which is similar to that of human GA. However, in experimental GA in rats (Vergnes et al., 1982), the spike-wave frequency is closer to $7-10 \mathrm{~Hz}$, so it is an oversimplification at this point to suggest that the intrathalamic oscillation studied in vitro is the only major mechanism underlying the timing of discharges in GA. Reasons for this discrepancy between in vitro and in vivo rhythms might include a somewhat lower temperature $\left(34^{\circ} \mathrm{C}\right)$ in the in vitro experiments, the presence of reentrant cortical excitation that occurs when the thalamocortical circuitry is intact, or influences of outputs of other circuits that impinge on the thalamus and cortex (Buzsaki et al., 1990).

There are some important differences between this type of network activity and that seen in ferret dorsal lateral geniculate slices (von Krosigk et al., 1993). Spontaneous spindle-like activity occurs in the latter, but was never seen in rat horizontal thalamic slices. This might be due to differences in connectivity in the two preparations. For example, because of fiber orientation and/or numbers of cells within the slice, there might be many more intact connections between GABAergic perigeniculate cells and geniculate relay cells in the ferret than between GABAergic nRt cells and VB relay neurons in the rat. In addition, the inhibitory local circuit interneurons present in the ferret geniculate may play a role in setting the level of spontaneous activity in the slice. Or perhaps there are fewer GABA receptors on ferret geniculate relay neurons. This latter possibility would explain why spindles are evoked with extracellular stimulation in the ferret slice, compared to slower rhythms in the rat slice where the potent $\mathrm{GABA}_{\mathrm{B}}$ potential prevents rebound excitation for periods of 200-300 msec.

The results of these experiments provide some information regarding mechanisms of synchronization and desynchronization within the thalamus. The extracellular stimuli we have applied provide synchronous inputs to a number of $\mathrm{nRt}$ cells. These evoke IPSPs in relay cells, some of which fire rebound bursts that activate additional $\mathrm{nRt}$ cells, and possibly including some that had been previously activated by the extracellular stimulation. Since nRt and VB in rat are both homogeneous populations with inhibitory and excitatory outputs, respectively, we conclude that this simple circuitry is all that is necessary for the generation of this slow rhythm. This contrasts with the underlying circuit in cat dorsal lateral geniculate where intranuclear inhibitory cells can evoke strong GABA $_{B}$ IPSPs (Crunelli et al., 1988), similar to the ones seen in VB secondary to $\mathrm{nRt}$ discharges in our experiments (e.g., Fig. 8 $A$ ). The other requirements for oscillation include depolarized membrane potentials (positive to $\sim-65 \mathrm{mV}$ ) in relay neurons so that rebound bursts can be triggered by IPSPs (e.g., Fig. $8 A, C$ ), and hyperpolarized $\mathrm{nRt}$ cclls (more negative than $\sim-70 \mathrm{mV}$ ), so that EPSPs from relay cell terminals will trigger bursts by activating LTSs (e.g.,
Fig. $8 D 1$ ). We speculate that these conditions are met during spike-wave activity through modulatory influences that are known to affect membrane potentials in VB and nRt neurons. For example, acetylcholine hyperpolarizes nRt cells (McCormick and Prince, 1986) and can depolarize relay cells (McCormick and Prince, 1987). Factors leading to the synchronous input that would initiate spike-wave discharges are not well understood, but it has been hypothesized that diffuse increases in cortical excitability might contribute (Gloor and Fariello, 1988).

Mechanisms probably exist in the thalamus to dampen this oscillation. For example, branch point failure might occur within axonal collatcrals of $\mathrm{nRt}$ or VB neurons, so that divergent synaptic output during each cycle would be weakened. Alternatively, resting membrane potentials in the component cells of the oscillation may undergo spontaneous fluctuations such that groups of relay neurons might not fire rebound bursts on some cycles because their resting membrane potentials are too negative to reach activation threshold for LTS generation as the IPSP decays. Similarly, nRt cells might become depolarized so that incoming EPSPs from VB would evoke single action potentials rather than bursts. We speculate that defects in such intrathalamic desynchronizing mechanisms might lead to generalized absence epilepsy. In this context, succinimides are such good therapeutic agents because their action introduces a small change in the intrathalamic circuit that facilitates the desynchronization process and therefore blocks synchronous spikewave activity. Consistent with this idea is the downregulation by ES of thalamic incrementing responses in cats (Pellegrini et al., 1989).

The basis for the waning nature of the oscillation (e.g., Fig. 10) in thalamic slices is unknown, but it is obviously a circuit phenomenon, that is, not just dependent on a damped intrinsic oscillation in thalamic cells. This is clear from results of experiments such as those of Figure 10 that shows that there are occasional failures in the midst of trains of oscillatory IPSCs, indicating periodic dropout of one or more $\mathrm{nRt}$ cells (or possibly branch point failure in $\mathrm{nRt}$ axons). Also, the recurrence of a fourth or fifth rebound IPSP after a failure of a third or fourth indicates that some $\mathrm{nRt}$ neurons can miss one cycle of the oscillation but still fire a burst on the subsequent cycle. The results of extracellular unit experiments (Fig. 9) were similar to those of the voltage-clamp experiments; some units would occasionally drop out from early cycles to reappear in later cycles. Current clamp experiments in VB (e.g., Fig. 8) showed that rebound IPSPs sometimes occurred at the same latency as rebound spike bursts, and therefore could inhibit them and contribute to desynchronization within the population.

\section{Effects of T-current modulation on thalamic oscillations}

We show here that antiepileptic succinimides decrease T-currents in both $\mathrm{nRt}$ and relay neurons within thalamic slices. Both indirect (current-clamp) and direct (voltage-clamp) measurements indicate that ES $(600-700 \mu \mathrm{M})$ reduces the amplitude of $I_{\mathrm{T}}$ by $30-40 \%$, without affecting the kinetics of activation or inactivation. This supports and generalizes the conclusions from earlier experiments performed in acutely isolated thalamic relay (Coulter et al., 1989b) and reticular (Huguenard and Prince, $1992 a)$ neurons from young (7-12-d-old) rats. Thus, interactions of succinimides with $I_{\mathrm{T}}$ channels are not somehow related to the isolation procedure itself or the maturity of animals. Effects of ES are, however, variable among different preparations. For 
example, while ES blockade of T-channels occurred in about $77 \%$ of isolated neurons (Coulter et al., 1989a), effects were clearly seen in every cell recorded from slices in this series of experiments. ES-responsive currents have also been reported in nodose ganglion cells (Macdonald and Meldrum, 1989) and in dorsal root ganglion cells (Kostyuk et al., 1992). By contrast, hippocampal neurons (Thompson and Wong, 1991) and thalamic neurons in dispersed culture (Pfrieger et al., 1992) were not sensitive to ES. This variability reflects either differences in the underlying $\mathrm{T}$-channels, or in recording conditions.

The reduction in T-current by succinimides was quite specific; there were no effects on resting potential, input resistance, the hyperpolarization-activated current, $I_{\mathrm{H}}$, or nonburst firing. From these data it seems likely that the major sites of action of succinimides in the brain will be nuclei whose neurons contain a sufficient density of T-channels to generate LTSs, such as, for example, inferior olive (Llinás and Yarom, 1981), substantia nigra (Llinás et al., 1984; Huguenard and Prince, 1992b), or lateral habenula (Huguenard et al., 1993). The specific anti-GA action is enhanced through interactions with two limbs of the recurrent thalamic circuit that both have prominent $\mathrm{T}$-currentdependent bursts; thus, succinimides would have stronger effects in the thalamus than in other nuclei where such a direct reciprocal connection between inhibitory and excitatory bursting cells may not be present.

Surprisingly, the ES-induced reduction in T-channel availability had little effect on burst output capability in thalamic relay or reticular cells (Fig. 3). The $\mathrm{Ca}^{2+}$-dependent bursts in both cell types are therefore quite robust; even when a third of the underlying $\mathrm{T}$-current is blocked, there appear to be sufficient "spare" channels available to generate full-fledged LTSs. However, under conditions of near-threshold stimuli (e.g., Figs. 3D, $8 A, C$ ) or reduced $\mathrm{T}$-channel availability, such as decreases in IPSPs from nRt (Fig. 10), or high-frequency activation that does not allow complete deinactivation of $I_{\mathrm{T}}$, some LTSs will be blocked or compromised. Thus, during the incompletely synchronized slow intrathalamic activity (e.g., see Figs. 9, 10), where there is dropout and then later reappearance of different units in the ensemble, succinimides will promote the desynchronization by increasing the number of dropouts. Thus, the subtle threshold effects on LTS threshold shown in Figure $3 D$ can produce robust antioscillatory actions in the ensemble circuitry (Figs. 9, 10).

From these findings we conclude that the major effect of $\mathrm{T}$-current blockade by ES occurs at the circuit level. By reducing burst probability, ES causes the thalamic circuit to become less synchronized. Similar effects of succinimides have been seen in an in vitro slice preparation that develops thalamocortical spikewave type activity (Coulter and Lee, 1992). Since spindles are also dependent on an intrathalamic oscillation (von Krosigk et al., 1993), by this reasoning they should be affected in the same way as the slow rhythms. We did not see spindle-type rhythms in rat somatosensory thalamic slices so we could not test this hypothesis; however, spindles are decreased by relatively high doses of ES in the cat (Pellegrini et al., 1989). We speculate that the effects of ES may be more specific for absence epilepsy than sleep spindles. Experimental evidence indicates that spindles are incompletely generalized, so that not every relay or reticular thalamic neuron fires on every intraspindle cycle (Steriade and Llinás, 1988; von Krosigk et al., 1993). Therefore, in the pause between bursts, $\mathrm{T}$-channels in each relay neuron can deinactivate to a greater extent than if they were firing on every, or nearly every, cycle. Spindles may then have a higher safety factor than slower pathophysiologic oscillations in which neurons are firing LTSs on every cycle (von Krosigk et al., 1993) and are unlikely to complete $T$-channel deinactivation during the interburst period. According to this argument, the slower, more synchronized oscillations that apparently characterize absence epilepsy would be more susceptible to dampening through partial T-channel blockade than would spindle activities, and this would explain the selective effect of succinimides on GA, and the reported lack of effect on human sleep spindles (Kellaway et al., 1991).

\section{References}

Andersen P, Andersson SA, Lomo T (1967) Nature of thalamo-cortical rclations during spontaneous barbiturate spindle activity. J Physiol (Lond) 192:283-307.

Avanzini G, de Curtis M, Panzica F, Spreafico R (1989) Intrinsic properties of nucleus reticularis thalami neurones of the rat studied in vitro. J Physiol (Lond) 416:111-122.

Avanzini G, de Curtis M, Marescaux C, Panzica F, Spreafico R, Vergnes $M$ (1992) Role of the thalamic reticular nucleus in the generation of rhythmic thalamo-cortical activities subserving spike and waves. J Neural Transm [Suppl] 35:85-95.

Avoli M, Kostopoulos G (1982) Participation of corticothalamic cells in penicillin-induced generalized spike and wave discharges. Brain Res 247:159-163.

Avoli M, Gloor P, Kostopoulos G, Gotman J (1983) An analysis of penicillin-induced generalized spike and wave discharges using simultaneous recordings of cortical and thalamic single neurons. J Neurophysiol 50:819-837.

Barker JL, Harrison NL (1988) Outward rectification of inhibitory postsynaptic currents in cultured rat hippocampal neurones. J Physiol (Lond) 403:41-55.

Blanton MG, Lo Turco JJ, Kriegstein AR (1989) Whole cell recording from neurons in slices of reptilian and mammalian cerebral cortex. J Neurosci Methods 30:203-210.

Burns BD (1950) Some properties of the cat's isolated cerebral cortex. J Physiol (Lond) 111:50-68.

Buzsaki G (1991) The thalamic clock: emergent network properties. Neuroscience 41:351-364.

Buzsaki G, Smith A, Berger S, Fisher LJ, Gage FH (1990) Petit mal epilepsy and parkinsonian tremor: hypothesis of a common pacemaker. Neuroscience 36:1-14.

Coulter DA, Lee C-J (1992) Physiological studies of thalamocortical rhythms, recorded in vitro in a brain slice preparation. Soc Neurosci Abstr 18:1391.

Coulter DA, Huguenard JR, Prince DA (1989a) Specific petit mal anticonvulsants reduce calcium currents in thalamic neurons. Neurosci Lett 98:74-78.

Coulter DA, Huguenard JR, Prince DA (1989b) Characterization of ethosuximide reduction of low-threshold calcium current in thalamic neurons. Ann Neurol 25:582-593.

Coulter DA, Huguenard JR, Prince DA (1989c) Calcium currents in rat thalamocortical relay neurones: kinetic properties of the transient, low-threshold current. J Physiol (Lond) 414:587-604.

Coulter DA, Huguenard JR, Prince DA (1990a) Differential effects of petit mal anticonvulsants and convulsants on thalamic neurones: calcium current reduction. Br J Pharmacol 100:800-806.

Coulter DA, Huguenard JR, Prince DA (1990b) Differential effects of petit mal anticonvulsants and convulsants on thalamic neurones: GABA current blockade. Br J Pharmacol 100:807-813.

Coulter DA, Huguenard JR, Prince DA (1991) Mechanism of block of thalamic "T"-type $\mathrm{Ca}^{2+}$ channels by petit mal anticonvulsants. Exp Brain Res 20:201-204.

Crunelli V, Haby M, Jassik Gerschenfeld D, Leresche N, Pirchio M (1988) $\mathrm{Cl}^{-}-$and $\mathrm{K}^{+}$-dependent inhibitory postsynaptic potentials evoked by interneurones of the rat lateral geniculate nucleus. J Physiol (Lond) 399:153-176.

de Curtis M, Spreafico R, Avanzini G (1989) Excitatory amino acids mediate responses elicited in vitro by stimulation of cortical afferents to reticularis thalami neurons of the rat. Neuroscience 33:275-283.

Deschênes M, Roy JP, Steriade M (1982) Thalamic bursting mech- 
anism: an inward slow current revealed by membrane hyperpolarization. Brain Res 239:289-293.

Domich L, Oakson G, Steriade M (1986) Thalamic burst patterns in the naturally sleeping cat: a comparison between cortically projecting and reticularis neurones. J Physiol (Lond) 379:429-449.

Dutar P, Nicoll RA (1988) A physiological role for $\mathrm{GABA}_{\mathrm{B}}$ receptors in the central nervous system. Nature 332:156-158.

Fisher RS, Prince DA (1977a) Spike-wave rhythms in cat cortex induced by parenteral penicillin. I. Electroencephalographic features. Electroencephalogr Clin Neurophysiol 42:608-624.

Fisher RS, Prince DA (1977b) Spike-wave rhythms in cat cortex induced by parenteral penicillin. II. Cellular features. Electroencephalogr Clin Neurophysiol 42:625-639.

Fukuda A, Prince DA (1992) Excessive intracellular $\mathrm{Ca}^{2+}$ inhibits glutamate-induced $\mathrm{Na}^{+}-\mathrm{K}^{+}$pump activation in rat hippocampal neurons. J Neurophysiol 68:28-35.

Fukuda A, Mody I, Prince DA (1993) Differential ontogenesis of presynaptic and postsynaptic GABA-B inhibition in rat somatosensory cortex. J Neurophysiol 70:448-552.

Gloor P, Fariello RG (1988) Generalized epilepsy: some of its cellular mechanisms differ from those of focal epilepsy. Trends Neurosci 11 : 63-68.

Gloor P, Guberman A, Sherwin AL (1975) Response of generalized penicillin epilepsy in the cat to ethosuximide and diphenylhydantoin. Neurology 25:758-764.

Hagiwara S, Ohmori H (1982) Studies of calcium channels in rat clonal pituitary cells with patch electrode voltage clamp. J Physiol (Lond) 331:232-252.

Hirsch JC, Burnod Y (1987) A synaptically evoked late hyperpolarization in the rat dorsolateral geniculate neurons in vitro. Neuroscience 23:457-468.

Hirsch JC, Fourment A, Marc ME (1983) Sleep-related variations of membrane potential in the lateral geniculate body relay neurons of the cat. Brain Res 259:308-312.

Hosford DA, Clark S, Cao Z, Wilson WA, Lin FH, Morrisett RA. Huin A (1992) The role of $\mathrm{GABA}_{\mathrm{B}}$ receptor activation in absence seizures of lethargic $(l h / l h)$ mice. Science 257:398-401.

Houser CR, Vaughn JE, Barber RP, Roberts E (1980) GABA neurons are the major cell type of the nucleus reticularis thalami. Brain Res 200:341-354.

Huguenard JR, Alger BE (1986) Whole-cell voltage-clamp study of the fading of GABA-activated currents in acutely dissociated hippocampal neurons. J Neurophysiol 56:1-18.

Huguenard JR, Prince DA (1992a) A novel T-type current underlies prolonged $\mathrm{Ca}^{2+}$-dependent burst firing in GABAergic neurons of rat thalamic reticular nucleus. J Neurosci 12:3804-3817.

Huguenard JR, Prince DA (1992b) Multiple sites of action of succinimides and related anticonvulsants. Epilepsia 33[Suppl 31:30.

Huguenard IR, Prince DA (1994) Clonazepam suppresses GABA ${ }_{B}$ mediated inhibition in thalamic relay neurons through effects in nucleus reticularis. J Neurophysiol, in press.

Huguenard JR, Hamill OP, Prince DA (1988) Developmental changes in $\mathrm{Na}^{+}$conductances in rat neocortical neurons: appearance of a slowly inactivating component. J Neurophysiol 59:778-795.

Huguenard JR, Coulter DA, Prince DA (1991) A fast transient potassium current in thalamic relay neurons: kinetics of activation and inactivation. J Neurophysiol 66:1304-1315.

Huguenard JR, Gutnick MJ, Prince DA (1993) Properties of low threshold calcium current in neurons isolated from the lateral habenula of the rat. J Neurophysiol 70:158-166.

Inoue M, Duysens J, Vossen JMH, Coenen AML (1993) Thalamic multiple-unit activity underlying spike-wave discharges in anesthetized rats. Brain Res 612:35-40.

Jahnsen H, Llinás R (1984) Electrophysiological properties of guineapig thalamic neurones: an in vitro study. J Physiol (Lond) 349:205226

Jasper HH, Droogleever-Fortuyn J (1947) Experimental studies of the functional anatomy of petit mal epilepsy. Assoc Res Nerv Ment Dis Proc 26:272-298.

Jones EG (1985) The thalamus. New York: Plenum.

Kellaway P (1985) Sleep and epilepsy. Epilepsia 26[Suppl 1]:S15-S30.

Kellaway P, Frost JD Jr, Mizrhi EM (1991) Ethosuximide effects on thalamic oscillating mechanisms, spindles, and generalized $3 \mathrm{~Hz}$ spike and wave bursts. Ann Neurol 30:293.

Kostyuk PG, Molokanova EA, Pronchuk NF, Savchenko AN, Ver- khratsky AN (1992) Different action of ethosuximide on low- and high-threshold calcium currents in rat sensory neurons. Neuroscience 51:755-758.

Liu Z, Vergnes M, Depaulis A, Marescaux C (1992) Involvement of intrathalamic $\mathrm{GABA}_{B}$ neurotransmission in the control of absence seizures in the rat. Neuroscience 48:87-93.

Livingstone M, Hubel D (1981) Effects of sleep and arousal on the processing of visual information in the cat. Nature 291:554.

Llinás R, Jahnsen H (1982) Electrophysiology of mammalian thalamic neurones in vitro. Nature 297:406-408.

Llinás R, Yarom Y (1981) Electrophysiology of mammalian inferior olivary neurones in vitro. Different types of voltage-dependent ionic conductances. J Physiol (Lond) 315:549-567.

Llinás R, Greenfield SA, Jahnsen H (1984) Electrophysiology of pars compacta cells in the in vitro substantia nigra-a possible mechanism for dendritic release. Brain Res 294:127-132.

Macdonald RL, Meldrum BS (1989) Principles of antiepileptic drug action. In: Antiepileptic drugs (Levy RH, Dreifuss FE, Mattson RH, Meldrum BS, Penry JK eds). New York: Raven.

McCormick DA, Huguenard JR (1992) A model of the electrophysiological properties of thalamocortical relay neurons. J Neurophysiol 68:1384-1400.

McCormick DA, Pape H-C (1990) Properties of a hyperpolarizationactivated cation current and its role in rhythmic oscillation in thalamic relay neurones. J Physiol (Lond) 431:291-318.

McCormick DA, Prince DA (1986) Acetylcholine induces burst firing in thalamic reticular neurones by activating a potassium conductance. Nature 319:402-405.

McCormick DA, Prince DA (1987) Actions of acetylcholine in the guinea pig and cat medial and lateral geniculate nuclei, in vitro. $\mathrm{J}$ Physiol (Lond) 392:147-165.

McCormick DA, Wang Z (1991) Serotonin and noradrenaline excite GABAergic neurones of the guinea-pig and cat nucleus reticularis thalami. J Physiol (Lond) 442:235-255.

McLachlan RS, Avoli M, Gloor P (1984a) Transition from spindles to generalized spike and wave discharges in the cat: simultaneous single-cell recordings in cortex and thalamus. Exp Neurol 85:413425.

McLachlan RS, Gloor P, Avoli M (1984b) Differential participation of some 'specific' and 'non-specific' thalamic nuclei in generalized spike and wave discharges of feline generalized penicillin epilepsy. Brain Res 307:277-287.

Mitrofanis J, Guillery RW (1993) New views of the thalamic reticular nucleus in the adult and developing brain. Trends Neurosci 16:240245.

Montero VM, Guillery RW, Woolsey CN (1977) Retinotopic organization within the thalamic reticular nucleus demonstrated by a double label autoradiographic technique. Brain Res 138:407-421.

Morison RS, Basset DL (1945) Electrical activity of the thalamus and basal ganglia in decorticate cats. J Neurophysiol 8:309-314.

Nowak L, Bregestovski P, Ascher P, Herbet A, Prochiantz A (1984) Magnesium gates glutamate-activated channels in mouse central neurones. Nature 307:462-465.

Otis TS, Mody I (1992) Modulation of decay kinetics and frequency of GABA-A receptor-mediated spontaneous inhibitory postsynaptic currents in hippocampal neurons. Neuroscience 49:13-32.

Otis TS, Staley KJ, Mody I (1991) Perpetual inhibitory activity in mammalian brain slices generated by spontaneous GABA release. Brain Res 545:142-150.

Otis TS, De Koninck Y, Mody I (1993) Characterization of synaptically elicited $\mathrm{GABA}_{\mathrm{B}}$ responses using patch-clamp recordings in rat hippocampal slices. J Physiol (Lond) 463:391-407.

Pape H-C, McCormick DA (1989) Noradrenaline and serotonin selectively modulate thalamic burst firing by enhancing a hyperpolarization-activated cation current. Nature 340:715-718.

Paxinos G, Watson C (1986) The rat brain in stereotaxic coordinates. Sydney: Academic

Pellegrini A, Ermani M, Testa G (1985) Involvement of cortical, thalamic and midbrain reticular formation neurons in spikc and wave discharges: extracellular study in feline generalized penicillin epilepsy. Exp Neurol 89:465-478.

Pellegrini A, Dossi RC, Dal Pos F, Ermani M, Zanotto L, Testa G (1989) Ethosuximide alters intrathalamic and thalamocortical synchronizing mechanisms: a possible explanation of its antiabsence effect. Brain Res 497:344-360. 
Pfrieger FW, Veselovsky NS, Gottmann K, Lux HD (1992) Pharmacological characterization of calcium currents and synaptic transmission between thalamic neurons in vitro. J Neurosci 12:4347-4357.

Pollen DA (1964) Intracellular studies of cortical neurons during thalamic induced wave and spike. Electroencephalogr Clin Neurophysiol 17:398-404.

Prince DA (1972) Topical convulsant drugs and metabolic antagonists. In: Experimental models of epilepsy-a manual for the laboratory worker (Purpura DP, Penry JK, Woodbury DM, Tower DB, Walter RD, eds), pp 51-83. New York: Raven.

Prince DA, Farrell D (1969) "Centrencephalic" spike-wave discharges following parenteral penicillin injection in the cat. Neurology 19:309310.

Shosaku A, Kayama Y, Sumitomo I, Iwama K (1989) Analysis of recurrent inhibitory circuit in rat thalamus: neurophysiology of the thalamic reticular nucleus. Prog Neurobiol 32:77-102.

Snead OC (1992) Evidence for $\mathrm{GABA}_{\mathrm{B}}$-mediated mechanisms in experimental generalized absence seizures. Eur J Pharmacol 213:343349.

Steriade M (1974) Interneuronal epileptic discharges related to spike and wave cortical seizures in behaving monkeys. Electroencephalogr Clin Neurophysiol 37:247-263.

Steriade M, Llinas RR (1988) The functional states of the thalamus and the associated neuronal interplay. Physiol Rev 68:649-742.

Steriade M, YossifG (1974) Spike-and-wave afterdischarges in cortical somatosensory neurons of cat. Electroencephalogr Clin Neurophysiol 37:633-648.

Steriade M, Oakson G, Diallo A (1976) Cortically elicited spike-wave after discharges in thalamic neurons. Electroencephalogr Clin Neurophysiol 41:641-644.
Thompson SM, Gahwiler BH (1992) Effects of the GABA uptake inhibitor tiagabine on inhibitory synaptic potentials in rat hippocampal slice cultures. J Neurophysiol 67:1698-1701.

Thompson SM, Wong RK (1991) Development of calcium current subtypes in isolated rat hippocampal pyramidal cells. J Physiol (Lond) 439:671-689.

Thompson SM, Deisz RA, Prince DA (1988) Relative contributions of passive equilibrium and active transport to the distribution of chloride in mammalian cortical neurons. J Neurophysiol 60:105-124.

Thomson AM (1988) Inhibitory postsynaptic potentials evoked in thalamic neurons by stimulation of the reticularis nucleus evoke slow spikes in isolated rat brain slices-I. Neuroscience 25:491-502.

Vergnes M, Marescaux C, Micheletti G, Reis J, Depaulis A, Rumbach L, Warter JM (1982) Spontaneous paroxysmal electroclinical patterns in rat: a model of generalized non-convulsive epilepsy. Neurosci Lett 33:97-101.

Vergnes M, Marescaux C, Depaulis A, Micheletti G, Warter JM (1987) Spontaneous spike and wave discharges in thalamus and cortex in a rat model of genetic petit mal-like seizures. Exp Neurol 96:127-136.

von Krosigk M, Bal T, McCormick DA (1993) Cellular mechanisms of a synchronized oscillation in the thalamus. Science 261:361-364.

Williams DA (1953) A study of thalamic and cortical rhythms in petit mal. Brain 76:50-69.

Williams S, Lacaille JC (1992) GABA-B receptor-mediated inhibitory postsynaptic potentials evoked by electrical stimulation and by glutamate stimulation of interneurons in stratum lacunosum-moleculare in hippocampal CA1 pyramidal cells in vitro. Synapse 11:249-258.

Zhang L, Spigelman I, Carlen PL (1991) Development of GABAmediated, chloride-dependent inhibition in CAl pyramidal neurones of immature rat hippocampal slices. J Physiol (Lond) 444:25-49. 